\title{
Research Paper \\ The Moderating Role of Subjective Well-Being on the Relationship of Goal Orienta- tion and Metacognition With the Academic Self-Efficacy of the Students
}

\author{
*Sahar Safarzadeh ${ }^{1}$ \\ 1. Assistant Professor, Department of Psychology, Ahvaz Branch, Islamic Azad University, Ahvaz, Iran.
}

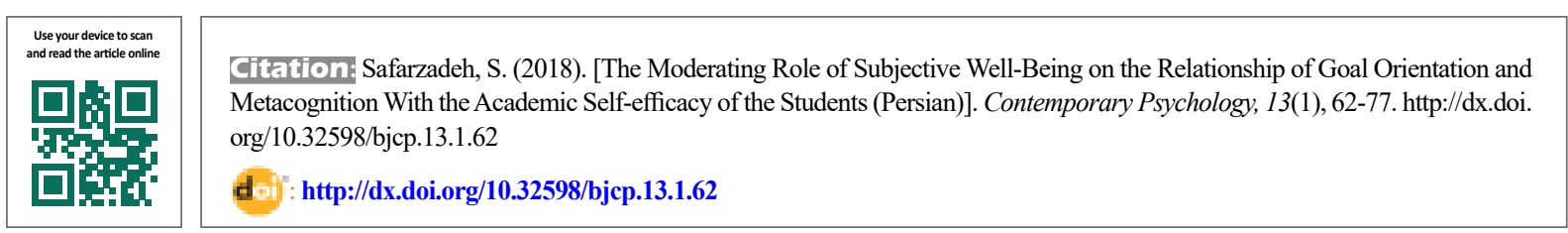

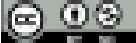

Received: 10 May 2017 Accepted: 13 Oct 2017 Available Online: 21 Mar 2018

Key words: Subjective, Well-being, Goals, Metacognition, Self-efficacy

\section{ABSTRACT}

Objectives The present study aimed to investigate the moderating role of subjective well-being on the relationship of goal orientation (skill-oriented, performance-oriented, performance-avoidance) and metacognition with the academic self-efficacy in students of Islamic Azad University, Ahvaz Branch, Ahvaz City, Iran.

Methods This was a cross-sectional research with correlational design. The study population comprised all students of Islamic Azad University Ahvaz Branch, Ahvaz City, Iran. The research sample included 400 students ( 200 boys and 200 girls), who were selected by multi-stage cluster sampling method. For the measurement of the study variables, goal orientation questionnaire, state metacognition inventory, satisfaction with life scale, and college academic self-efficacy scale were used.

Results The results of the Pearson correlation coefficient indicated a significant correlation $(P<0.0001)$ between subjective well-being, goal orientation (skill-oriented, performance-oriented, performanceavoidance) and metacognition with academic self-efficacy among the students. Moreover, the adjusted regression analysis indicated that subjective well-being had an adjusting role on the relationship of goal orientation and metacognition with the academic self-efficacy.

Conclusion The relationship between goal orientation (skill-oriented, performance-oriented, performance- avoidance) and metacognition with academic self-efficacy is not a simple linear associ-ation but adjusted and moderated by subjective well-being.

* Corresponding Author:

Sahar Safarzadeh, PhD.

Address: Department of Psychology, Ahvaz Branch, Islamic Azad University, Ahvaz, Iran. Tel: +98 (916) 3049476

E-mail: safarzadeh1152@yahoo.com 


\title{
نقش تعديلكنتده احساس بهزيستى ذهنى در رابطه جهت

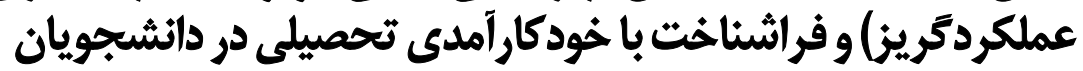

• سحر صفرزاده

1- استاديار، كروه روانشناسى، واحد اهواز، دانشعاه آزاد اسلامى، اهواز، ايران.

\begin{abstract}
حكיد

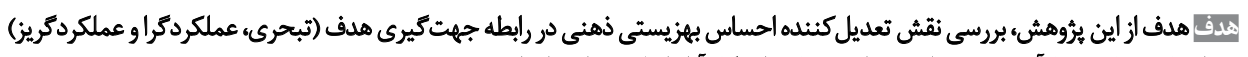

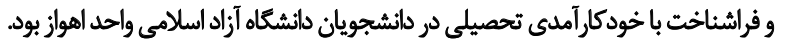

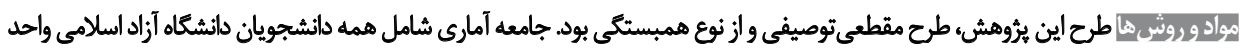

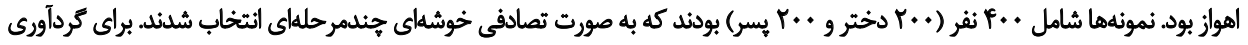

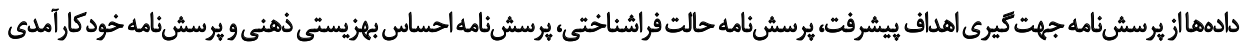

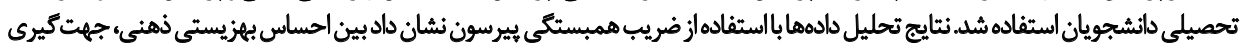

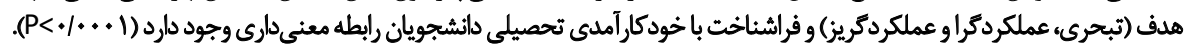

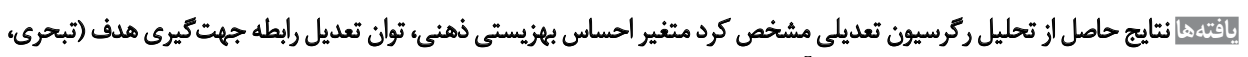

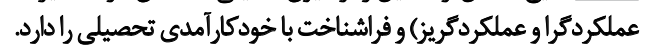

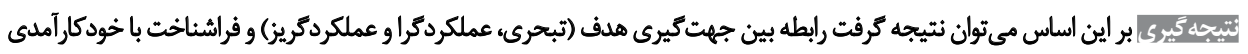

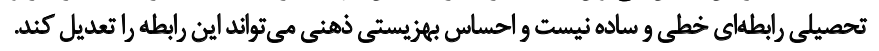

تاريخ دريافت: +rارديبهت

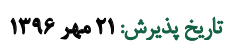

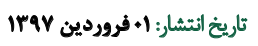

خودكار آمدى و خودتنظيمى دانشجويان را افزايش دهند و باعث dales

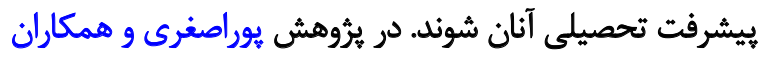

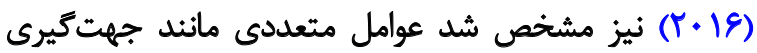

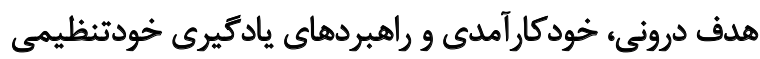

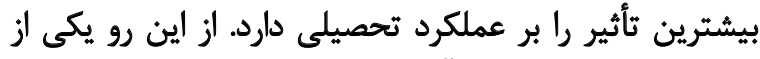

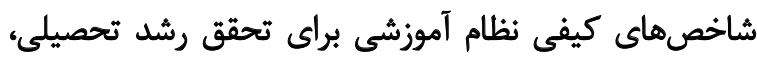

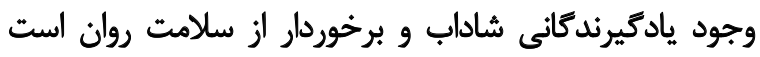

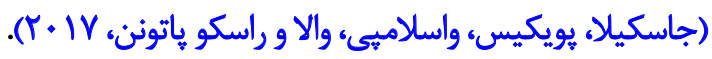

با نكاهى دقيق به عوامل مؤثر بر بيشرفت تحصيلى به اين اين نكته

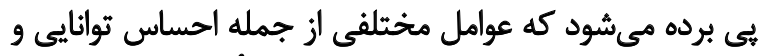

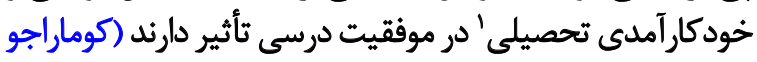

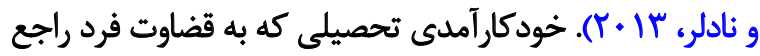

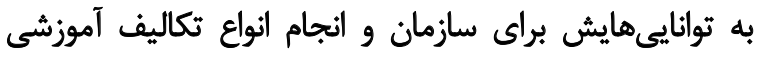

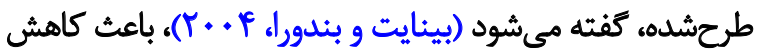

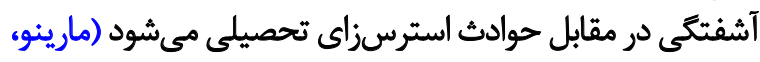

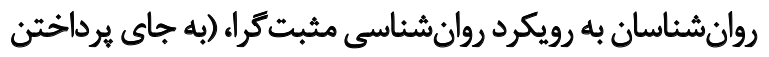

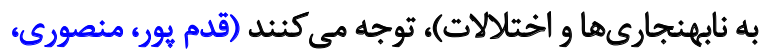

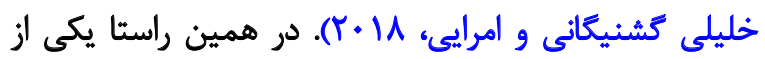

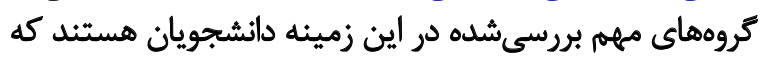

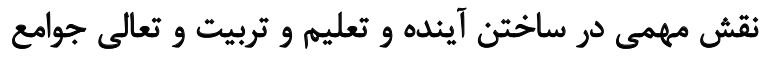

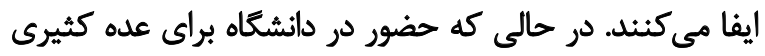

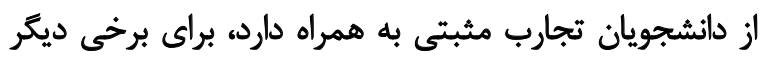

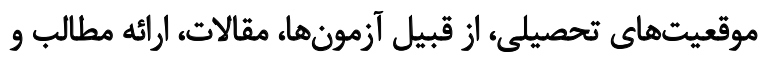

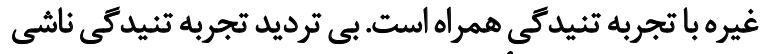

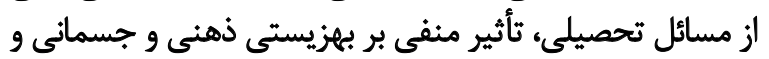

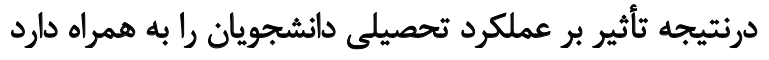

$$
\text { (فراهانى، } 9 \text { + + (r). }
$$

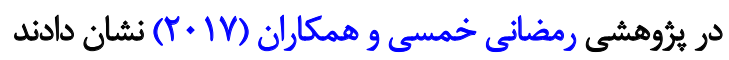

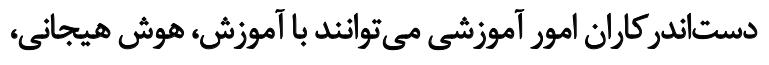




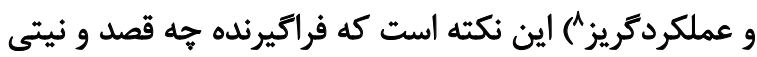

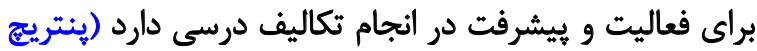

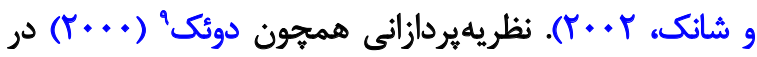

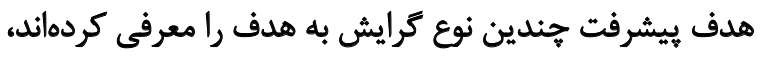

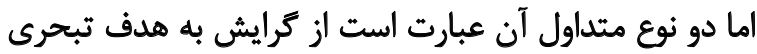

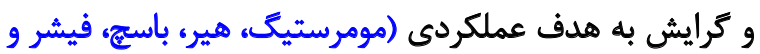

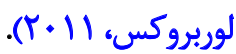

افرادى كه انتيزههاى تبحرى دارند معمولاً شايستكى خود

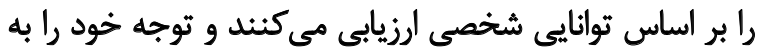

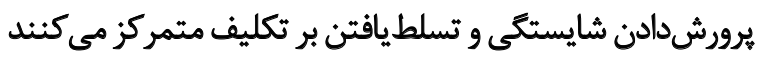

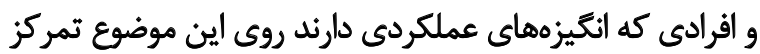

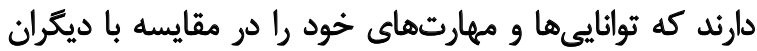

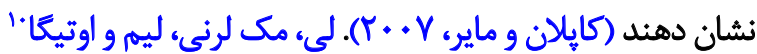

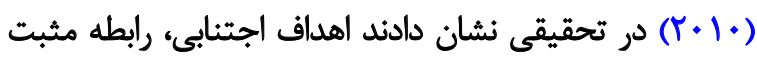

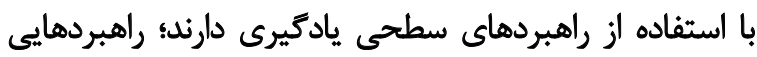

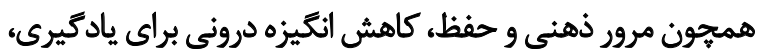

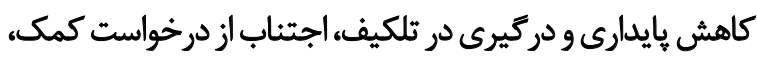

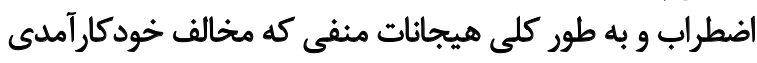

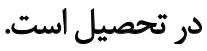
انكيزههاى تبحرى، در موقعيتهاى بيشرفت (براى مثال، در

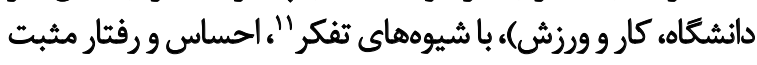

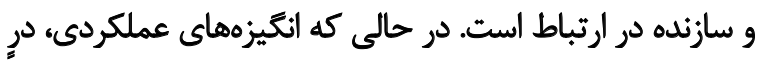

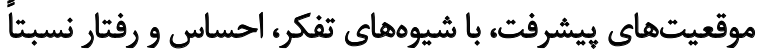

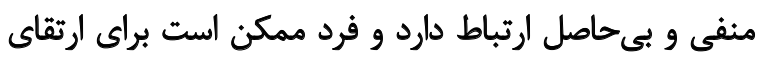

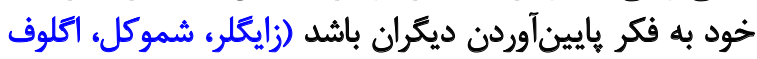

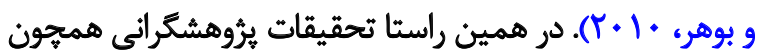

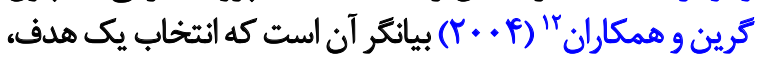

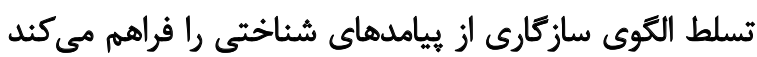

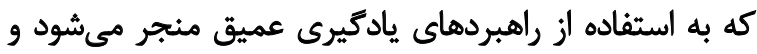

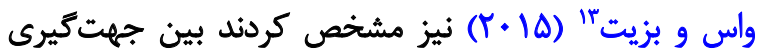

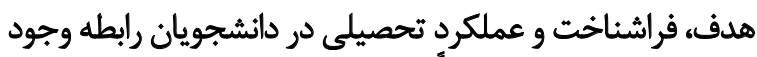

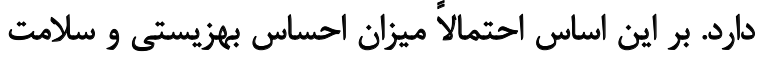

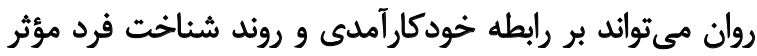

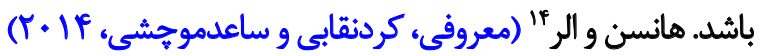

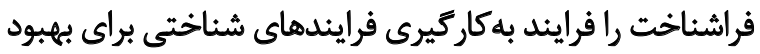

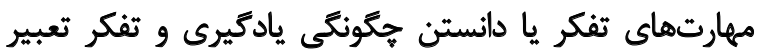

8. Skill-Oriented, performance-orientation \& performanceavoidance

9. Dweck

10. Lee, McInerney, Liem \& Ortiga

11. Thinking style

12. Greene, Miller, Crowson, Duke \& Akey

13. Was \& Beziat

14. Eller

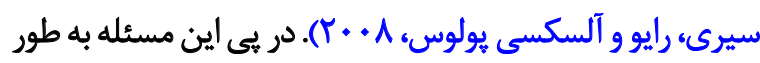

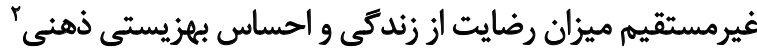
در فرد تغيير مى كند (كارول و همكاران، و ه. +.). مفهوم رضايت و احساس بهزيستى ذهنى، تجربه درونى مئى

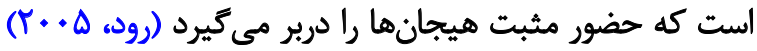

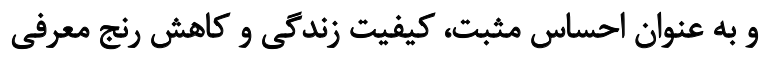

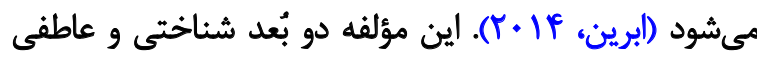

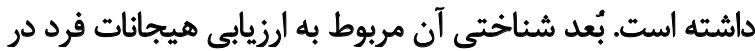

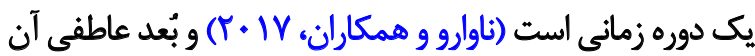

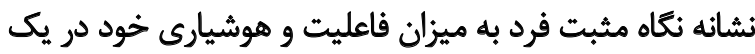

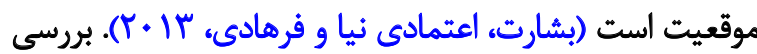

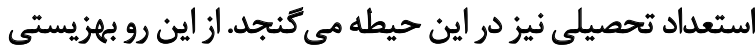

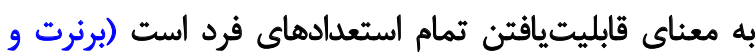

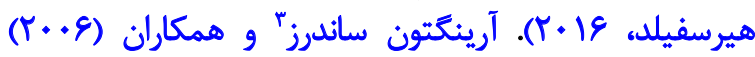

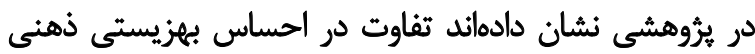

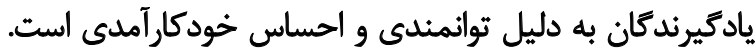

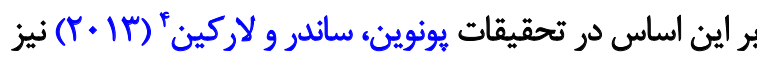

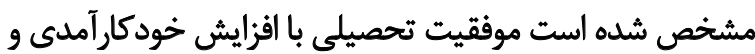

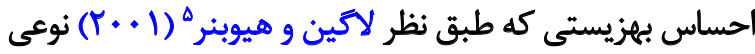

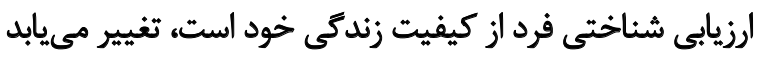

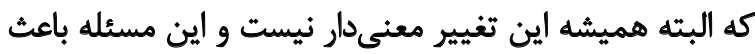
خلأيى در علم شده است.

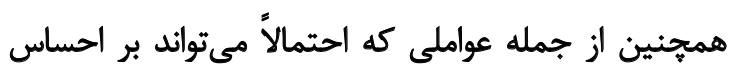

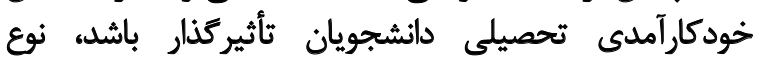

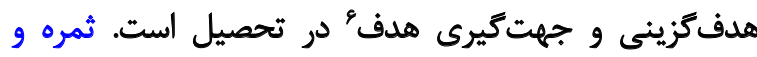

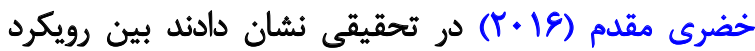

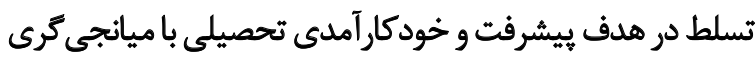

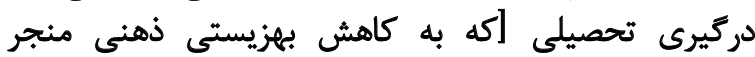

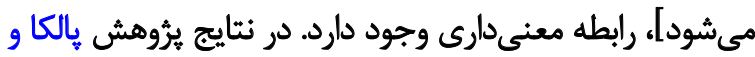

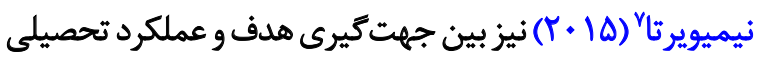

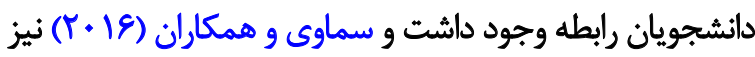

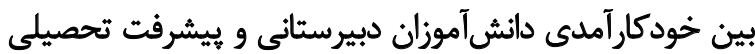
آنان رابطه معنى دار نشان دادهاند.

در كل نظريه هدف نرايي يا جهت كيرى اهداف از جمله

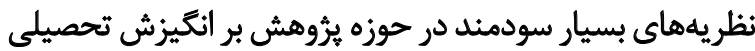
است. هسته مفهومى نظريه هدف كرايى (تبحرى، عملكردئرا

2. Subjective well-being

3. Arrington-Sanders

4. Putwain, Sander \& Larkin

5. Loughlin \& Huebner

6. Goal orientation

7. Pulkka \& Niemivirta 


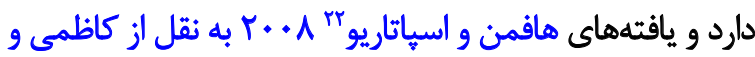

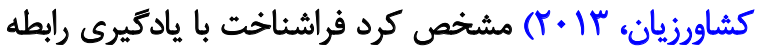

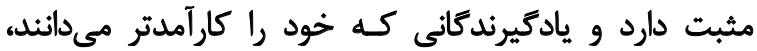

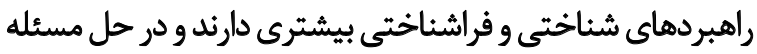

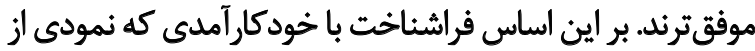

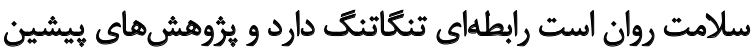

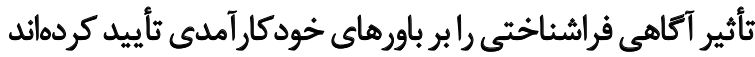

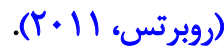

يادكيرندكان با قضاوتهاى فراشناختى، برآوردى از مقتضيات

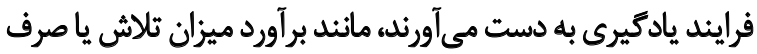
وقت در انجام تكليف يا انتخاب راهبرد مناسب يادئ يادكيرى (افليدزن،

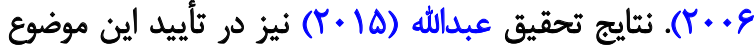

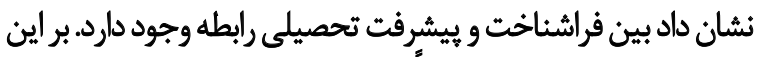

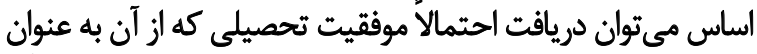

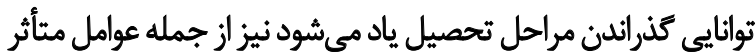

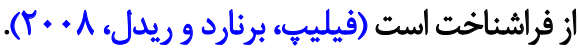

اما هيجكدام از تحقيقات به طور مستقيم نشان ندادند كه آيا تهني

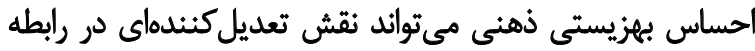

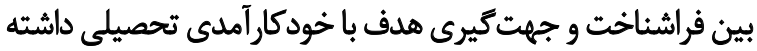

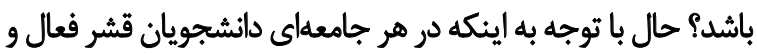

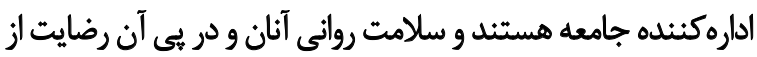

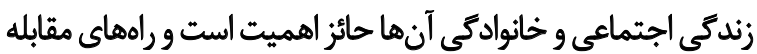

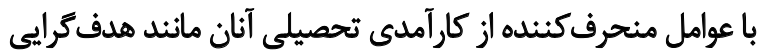

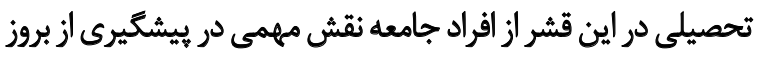

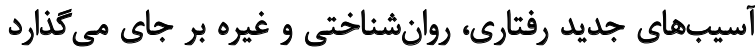

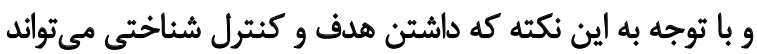

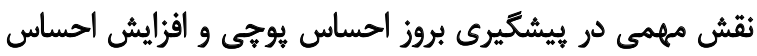

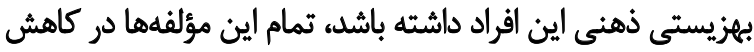

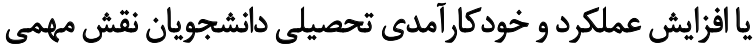

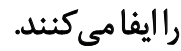

بر اين اساس اين تحقيق به دنبال باسخ به اين سؤال است

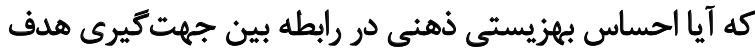

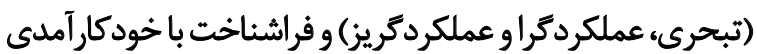

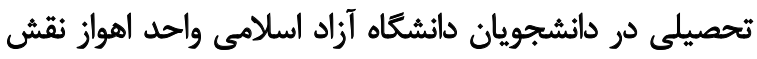

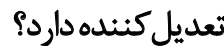

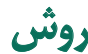

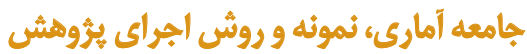
اين يرؤوهش از جمله تحقيقات كاربردىاى است كه بر مبناي

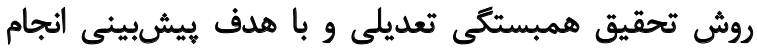

22. Hofman \& Spatarioo

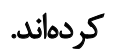

در بررسى انجامشده از سوى كارشكى و ياكميهر (11)

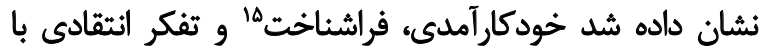

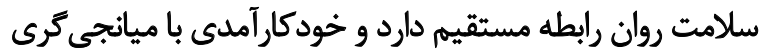

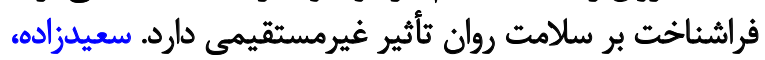

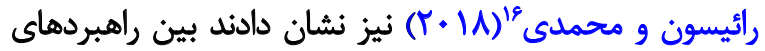

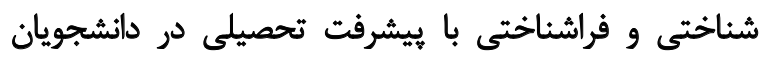

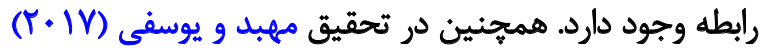

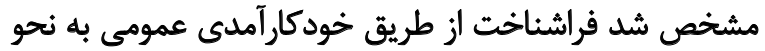

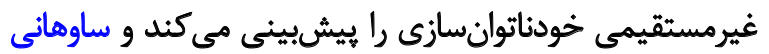

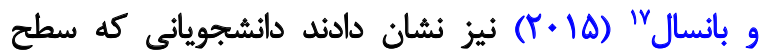
فراشناخت بيشترى دارند بيشرفت و خودكارآمدى تحصيلى نيلى نيان بيشترى رانشان مي دهند.

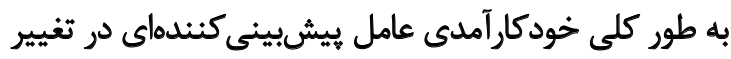

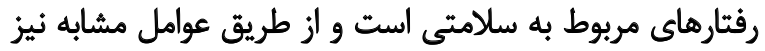

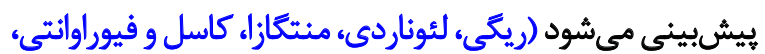
مهارت (T.1.

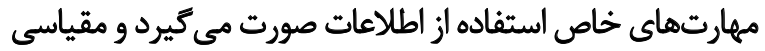

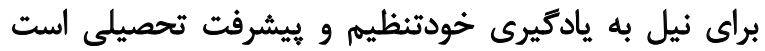

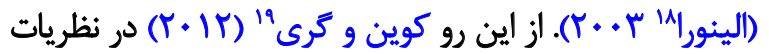

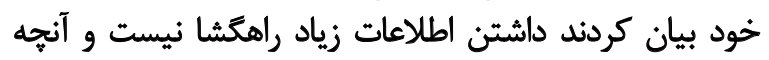

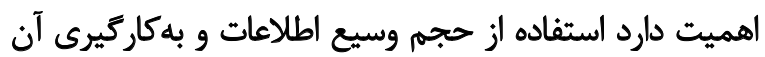

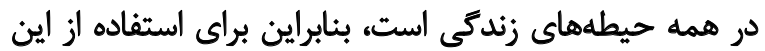

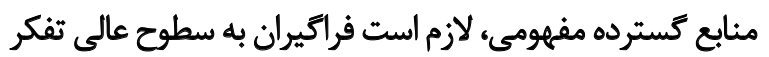

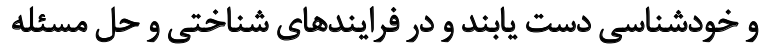
كه از نمودهاى فراشناخت است، تبحر كافى داشته باشند.

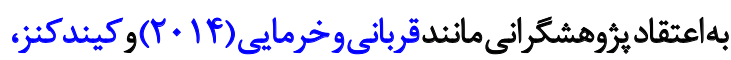

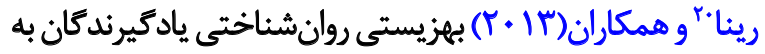

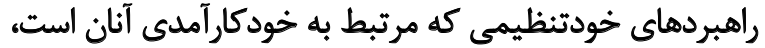

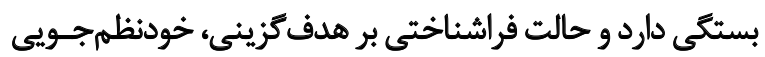

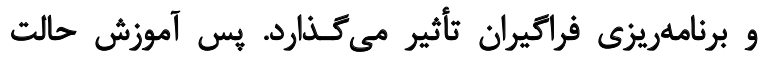

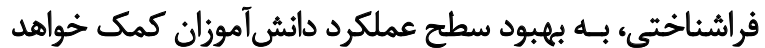

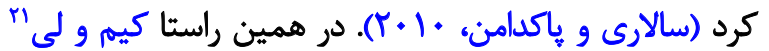

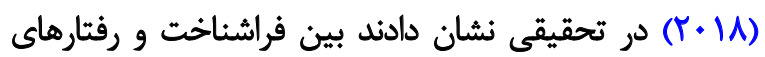

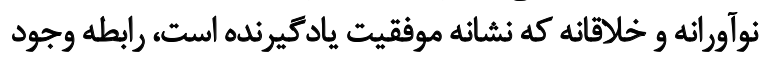

15. Metacognition

16. Saeedzadeh, Raeisoon \& Mohammadi

17. Sawhney \& Bansal

18. Eleonora

19. Kevin \& Gary

20. Kindekens, Reina, De Backer, Peeters, Buffel \& Lombaerts

21. Kim \& Lee 
و • بورد كه حاكى از هاياييى قابل قبول آن است. يرسش نامه احساس بهزيستى ذهنى

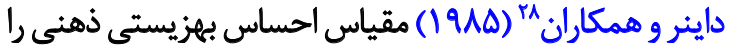

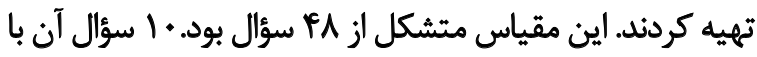

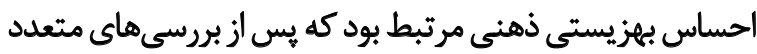

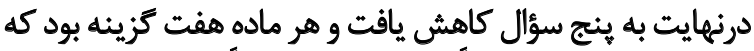

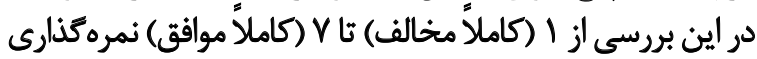

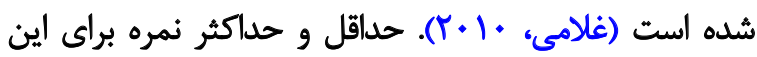

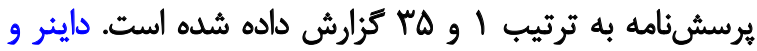

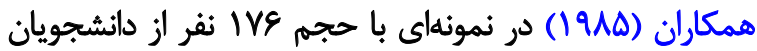

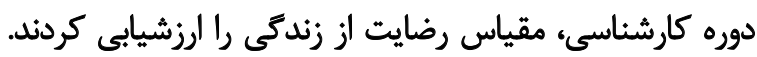

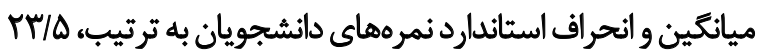

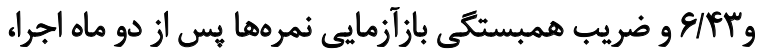

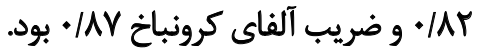

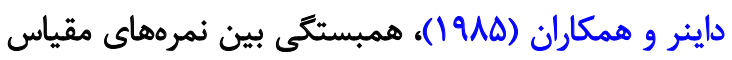

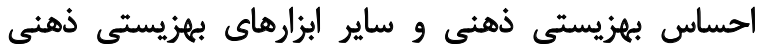

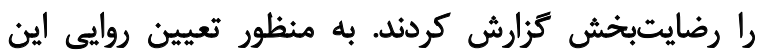

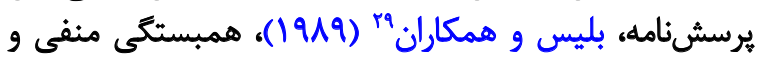

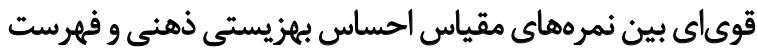

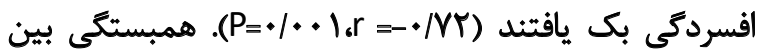

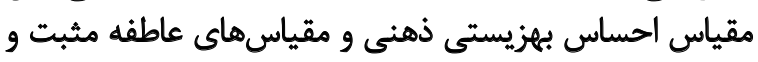

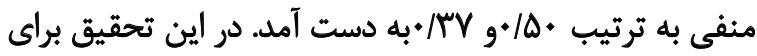

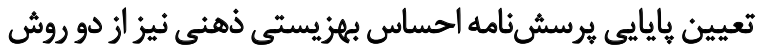

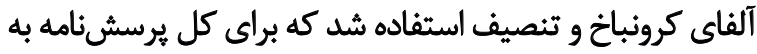

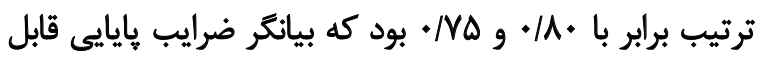
قبول يرسشنامه يادشده است

\section{هرسشنامه جهت هيرى اهداف بيشرفت ميدكلى و

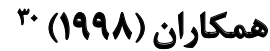

يرسشنامه جهت كيرى هدف ميدكلى و همكاران (1991)

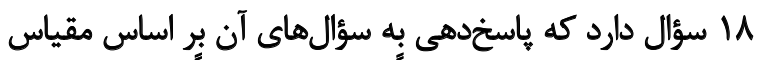

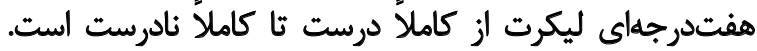

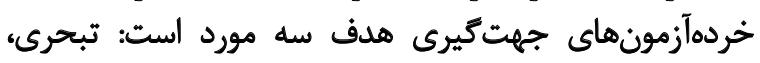

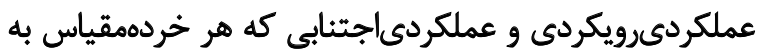

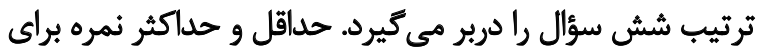

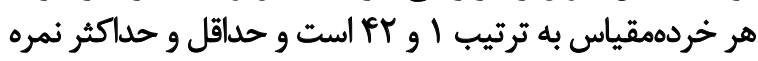
براى كل يرسشنامه | و و ع است است.

در تحقيق ميدكلى و همكاران (1991) بإيايى خردهآزمونهاى

27. Satisfaction With Life Scale (SWLS)

28. Diener, Emmons, Larsen \& Grrifen

29. Blais, Valerand, Pelletier \& Briere

30. Midgley's Goal Orientation Questionnaire

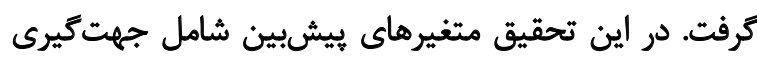

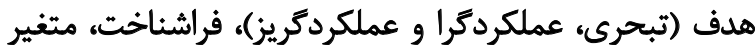

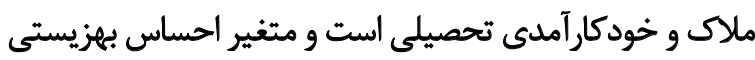

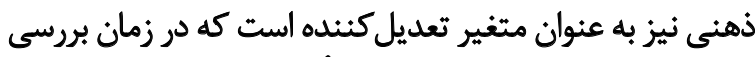

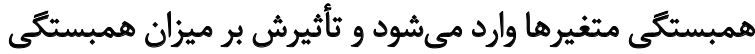

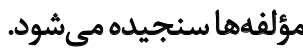

جامعه آمارى اين بروهش شامل تمام دانشجويان دانشعاه آزاد

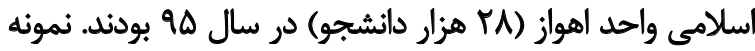

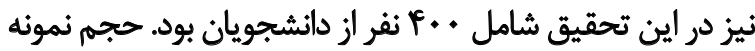

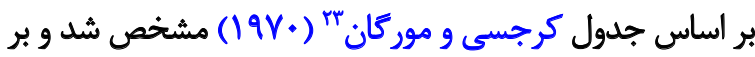

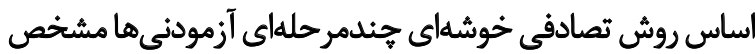

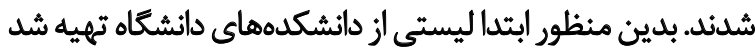

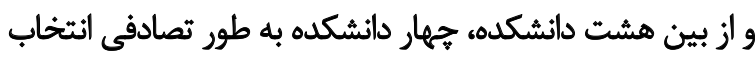

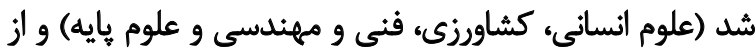

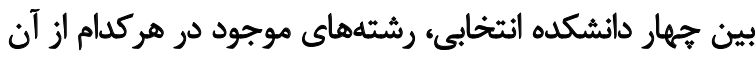

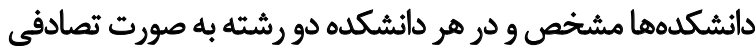

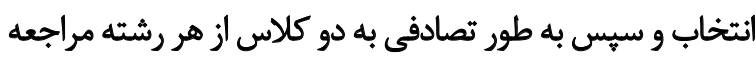

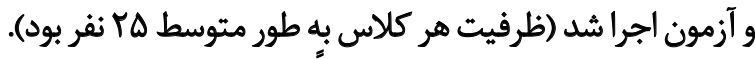

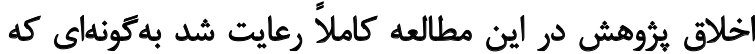

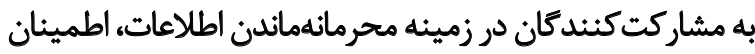

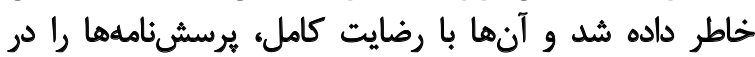
محيطى آرام و بدون ذكر نام تكميل كردند.

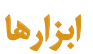

\section{يرسش نامه خودكار آمدى تحصيلى دانشجويان}

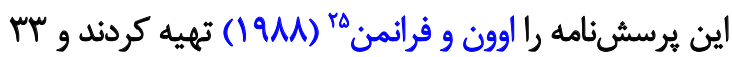

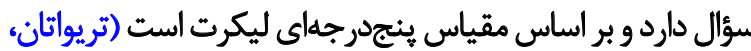

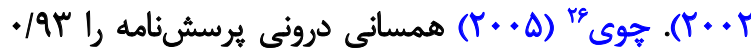

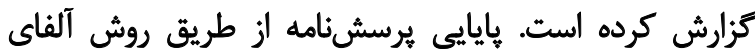

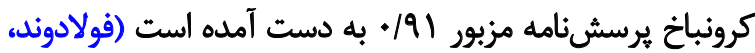

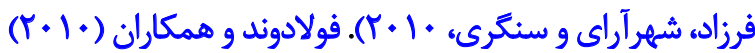

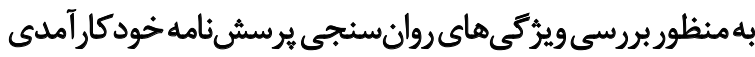

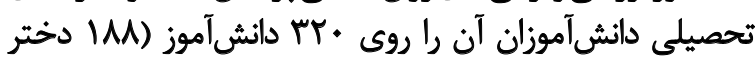

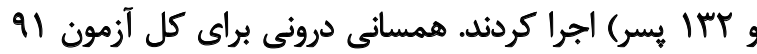

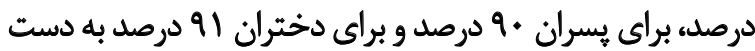

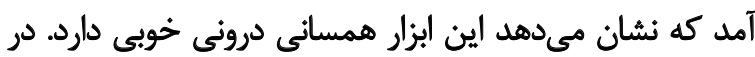

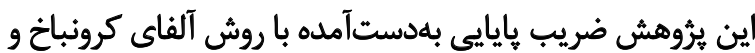

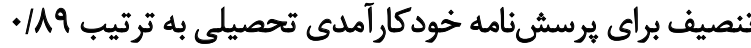

23. Krejcie \& Morgan

24. Colleg Academic Self-Efficacy Scale (CASE)

25. Owen \& Froman

26. Choi 


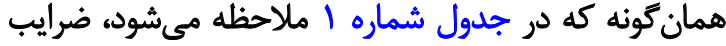

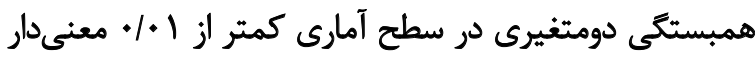

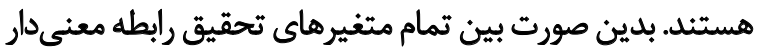

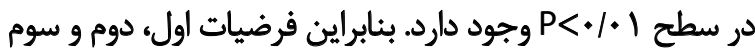

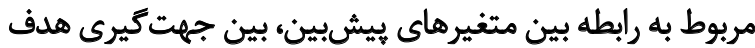

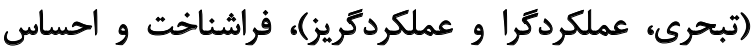

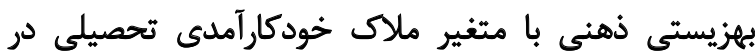

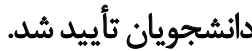

فرضيه جهارم:احساس بهزيستى ذهنى رابطه بين هدفترايى

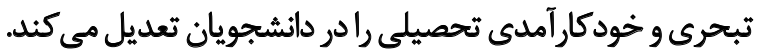

نتايج تحليل ركرسيون تعديلى به منظور بررسى نقش

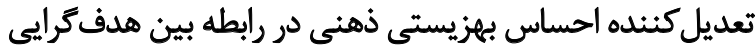

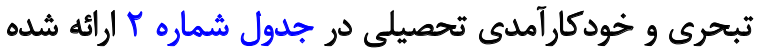

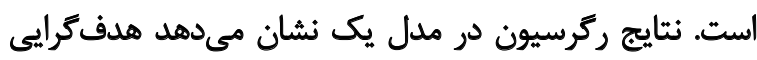

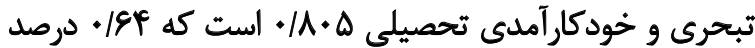

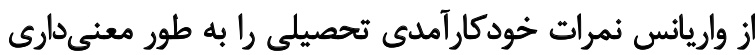

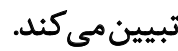

مدل دو نشان مى دهد رابطه متغيرهاى هدفترايى تبحرى و و

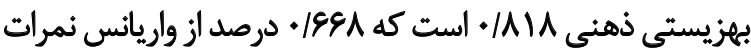

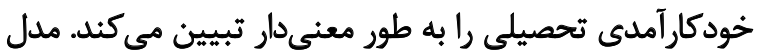

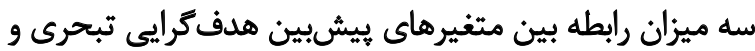

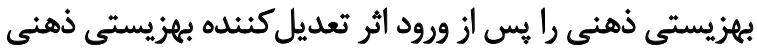

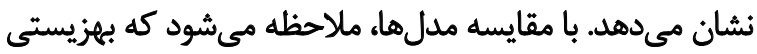

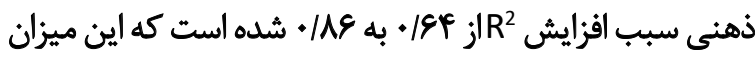
معنى دار است (P)

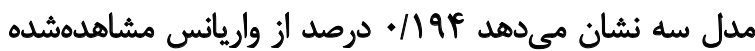

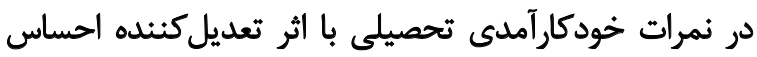

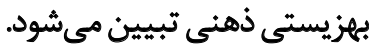

ضرايب استاندارد و غيراستاندارد تحليل ركرسيون در جدول إئل

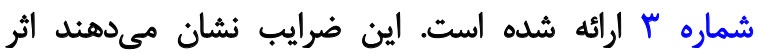
تعديل كنئده احساس بهزيستى ذهنى (t)

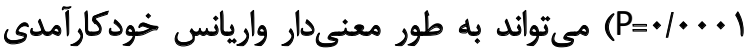
تحصيلى راتبيين كند.

فرضيه يُجم: احساس بهزيستى ذهنى رابطه بين هدف تركرايى

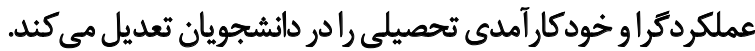

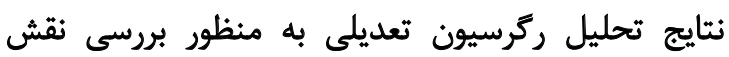

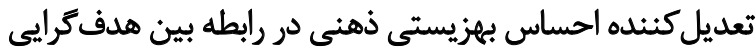

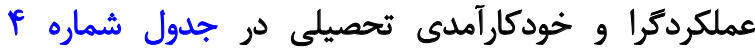

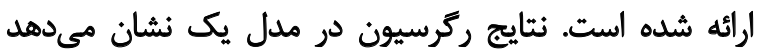

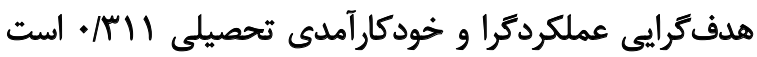

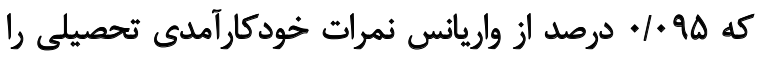

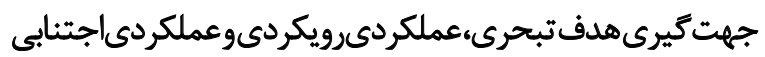

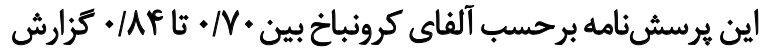

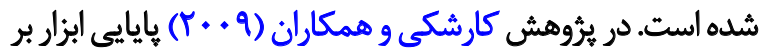

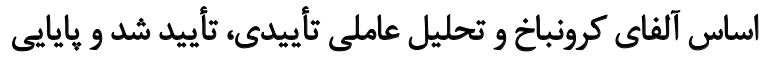

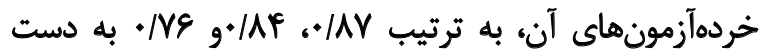

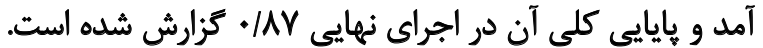

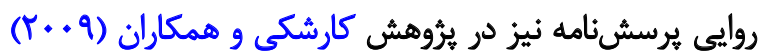
با استفاده از تحليل عاملى تأييدى و اكتشافى احراز شده واست

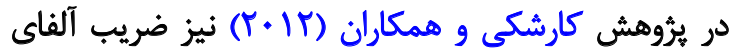

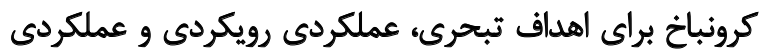

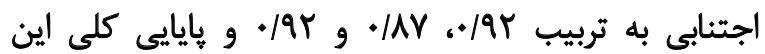

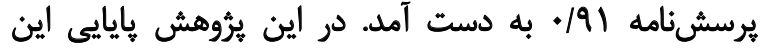

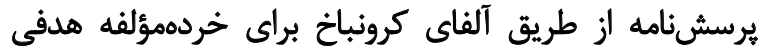

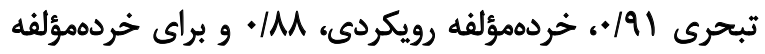

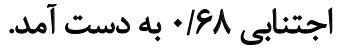

\section{"يرسشنامه حالت فراشناختى"}

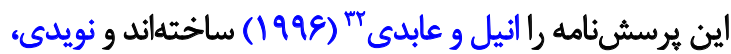

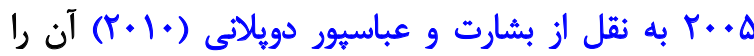

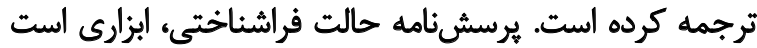

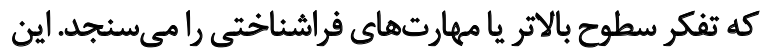

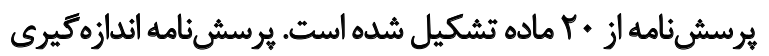

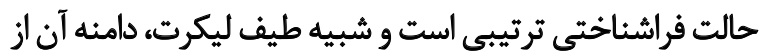

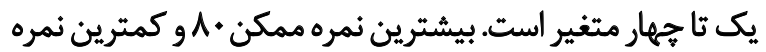

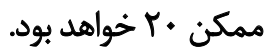

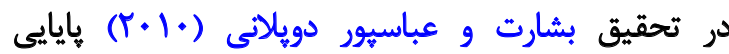

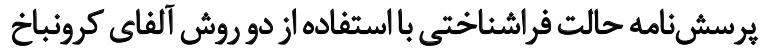

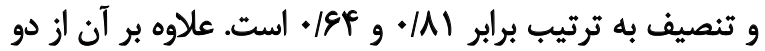

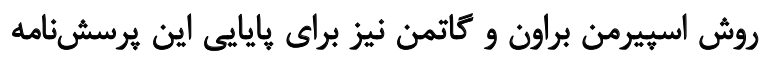

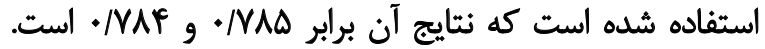

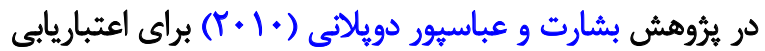

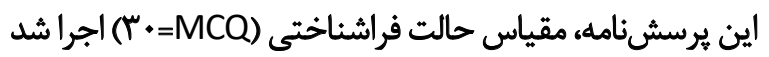

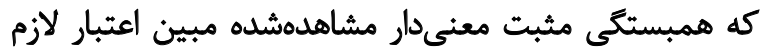

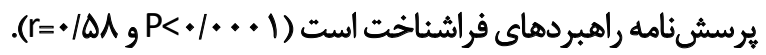

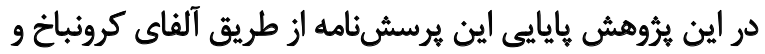

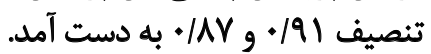

يافتها

يافتههاى توصيفى شامل ميانگين، انحراف استانداردو يافتههاى تحليل همبستخى بيرسون در جدول شماره ا ارائه شده است.

31. State Metacognitin Invertory

32. O'Neill \& Abedi 
جدول ا. ماتريس همبستكى بين متغيرها

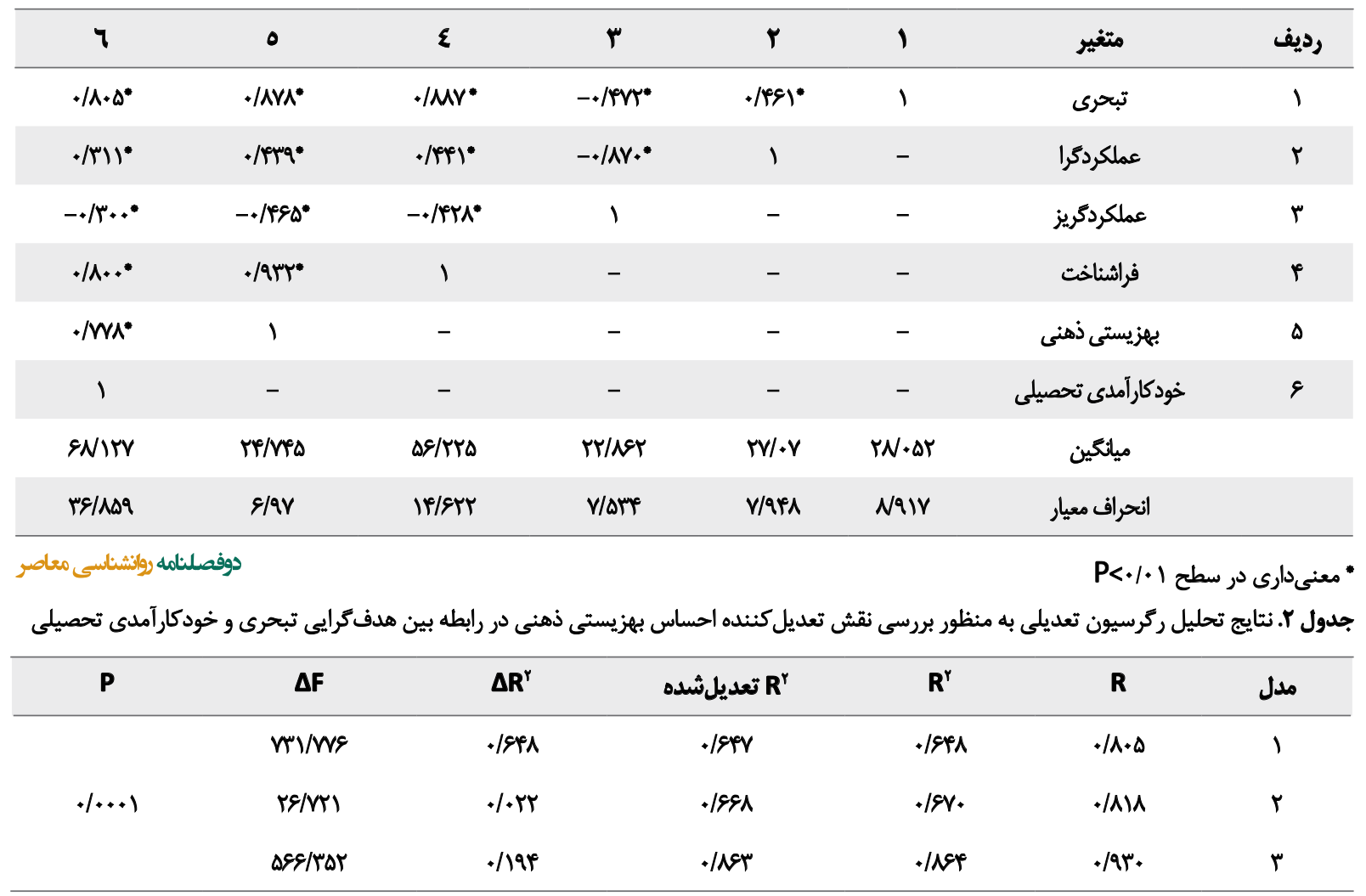

دوفصلنامه روايشناسى معاصر

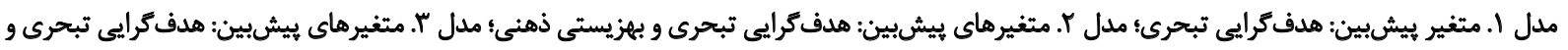

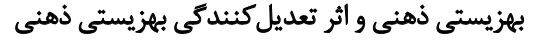

بهزيستى ذهنى نشان مي دهد. با مقايسه مدل ها، ملاحظه مي شيود

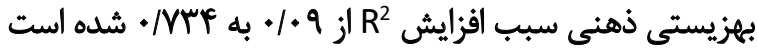

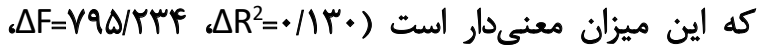

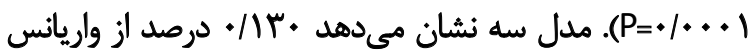

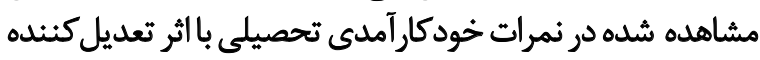

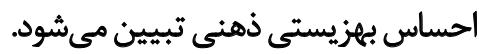

به طور معني دارى تبيين مي كئد. مدل دو نشان مي مدهد رابطه

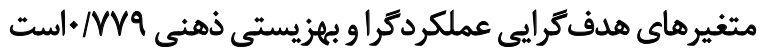

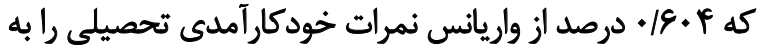
طور معنى دار تبيين مي كند. درو

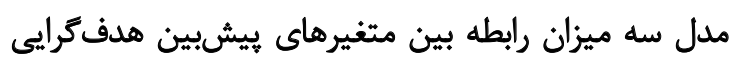

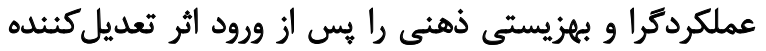

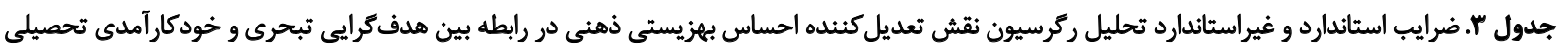

\begin{tabular}{|c|c|c|c|c|c|}
\hline $\mathbf{P}$ & $\mathbf{t}$ & $\beta$ & SE & B & مثيرهاى ييشبين \\
\hline$+1+++1$ & $|V|+\Delta \mid$ & $+/ \Lambda+\Delta$ &.$/ 1 r$ & T/Mr & هدف كرايى تبحرى \\
\hline $.1 \ldots 1$ & NAYE & . IAMT &.$/ r e q$ & r/IqV & هدف كرايى تبحرى \\
\hline$+1+.+1$ & $\Delta / 189$ &.$/ m 11$ &.$/ M M$ & Vepe & مبزيستى ذهنى \\
\hline$+1+\cdots+1$ & $-11 / r+r$ & $-\cdot M r \wedge$ &.$/ M r$ & $-r / \cdot \Delta r$ & هدف كرايي ثبحرى \\
\hline $.1+.+1$ & $-V / / r e$ & 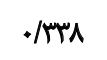 &.$/ r a$ & $-1 / N A E$ & 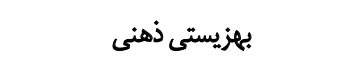 \\
\hline $.1 . . .11$ & MTIVA & $1 / 917$ & $\cdot 1 \cdot \cdot 1$ &.$M M$ & هدف كرايي تبحرى × بيزيستى ذهنى \\
\hline
\end{tabular}

دوفصلنامه وزانشناسى معاصر 
جدول F. نتايج تحليل ركرسيون تعديلى به منظور بررسى نقش تعديل كننده احساس بهزيستى ذهنى در رابطه بين هدف ترايى عملكردكرا وخودكار آمدى تحصيلى

\begin{tabular}{|c|c|c|c|c|c|c|}
\hline $\mathbf{P}$ & $\mathbf{\Delta F}$ & $\Delta \mathbf{R}^{r}$ & تعديلشده & $\mathbf{R}^{r}$ & $\mathbf{R}$ & مدل \\
\hline & Fr/FAD & +1.97 & .1 .90 & $+1+94$ &.$/ M 11$ & 1 \\
\hline \multirow[t]{2}{*}{$.1 . . .1$} & $\Delta 1 Y / V^{E} \Delta$ & .10 .9 & $.18 . p$ & .18 .8 & M M & $r$ \\
\hline & $V q \Delta / m m e$ &.$/ 1 \%$ & . Mn &.$/ M^{\prime}$ & - $\mid A \Delta A$ & $r$ \\
\hline
\end{tabular}

دوفصلنامه روائشناسى معاصر

مدل ا. متغير بيشبين: هدف كرايى عملكردكرا

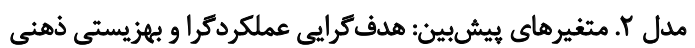
مدل ب. متغيرهاى بيشبين: هدف كرايى عملكردكرا و بهزيستى ذهنى و اثر تعديل كنندكى بهزيستى ذهنى جدول ه. ضرايب استاندارد و غيراستاندارد تحليل ركرسيون نقش تعديل كنئده احساس بهزيستى ذهنى در رابطه بين هدفترايى عملكردكرا وخودكار آمدى تحصيلى

\begin{tabular}{|c|c|c|c|c|c|}
\hline $\mathbf{P}$ & $\mathbf{t}$ & $\beta$ & SE & B & متغيرهاى بيشبين \\
\hline$+1+\cdots+1$ & g/AMf & $\cdot / M$ &.$/ M Y I$ & l/Afr & هدف كرايع عملكردكرا \\
\hline.$/ Y A$ & $-1 / \cdot 11$ & $-.1 \cdot \% A$ &.$/ 1 E r$ &.$- / 1 v 8$ & هدف كرايي عملكردكرا \\
\hline $.10 .+1$ & Mrege &.$/$ Mas &.$/ M A$ & f/r.r & مهزيستى ذهنى \\
\hline $.1+.+1$ & $-|r / M|$ & $-\cdot M r r$ & . MEX & $-r / r \Delta l$ & هدف كرايي عملكردكرا \\
\hline .1 .49 & $r / .89$ &.$/ 118$ & . /ru & . Ieiv & مهزيستى ذهنى \\
\hline $.1 \ldots 1$ & $15 / 94$ & $1 / r I I$ & $.1 \cdot 11$ &.$/ \Delta \Delta r$ & هدف كرايع عملكردترا × بيزيستى ذهنى \\
\hline
\end{tabular}

دوفصلنامه ووانشناسى معاصر

خودكارآمدى تحصيلى در جدول شماره \& ارائه شده است. نتايج

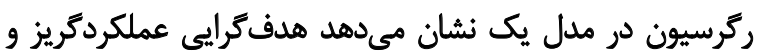

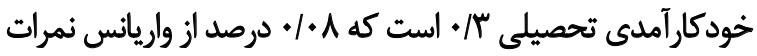

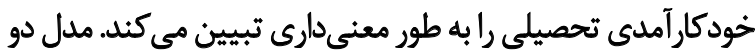

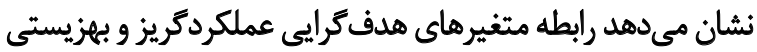

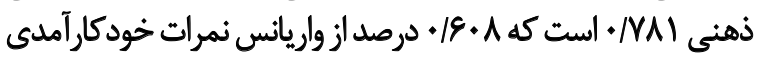
تحصيلى را به طور معنى دار تبيين مي كند. أند

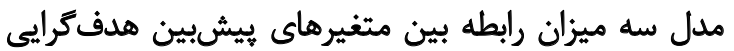

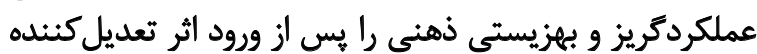

ضرايب استاندارد و غيراستاندارد تحليل ركرسيون در جدول

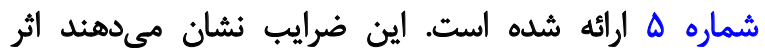

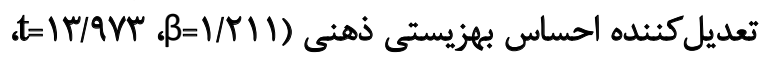

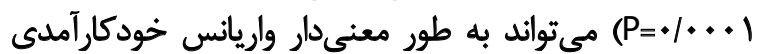
تحصيلى راتبيين كند. فرضيه ششهم: احساس بهزيستي ذهني رابطه بين هدف كرايي

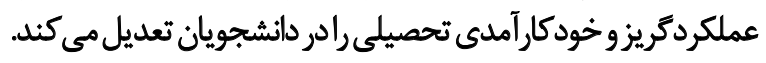
نتايج تحليل ركرسيون تعديلي به منظور بررسي نقش تعديل كنينده

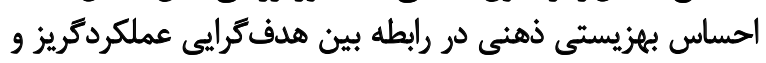

جدول و. نتايج تحليل ركرسيون تعديلى به منظور بررسى نقش تعديل كننده احساس بهزيستى ذهنى در رابطه بين هدف كرايى عملكردمريز و خودكارآمدى تحصيلى

\begin{tabular}{|c|c|c|c|c|c|c|}
\hline $\mathbf{P}$ & $\Delta \mathbf{F}$ & $\Delta \mathbf{R}^{r}$ & تعديلشُشه & $\mathbf{R}^{r}$ & $\mathbf{R}$ & هدل \\
\hline$+1+\ldots 1$ & ma/ror & 1.9. & $.1+A V$ & 1.9. & $. / \mu+$. & 1 \\
\hline$+1 \ldots 1$ & arq/We & . /QT. & $\cdot 18 \cdot 1$ &.$|8|$. & . $/ \mathrm{YAI}$ & $r$ \\
\hline$+1+++1$ & $r r+A r \Delta$ & $+/ N F$ & - MPA & + $/$ Va & - INES & $r$ \\
\hline
\end{tabular}

دوفصلنامه روانشناسى معاصر

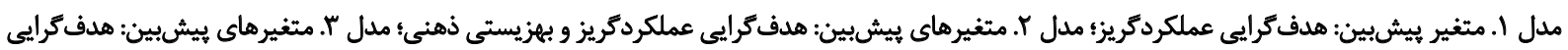

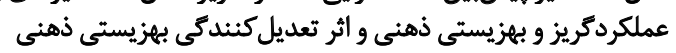


جدول Y. ضرايب استاندارد وغيراستاندارد تحليل ركرسيون نقش تعديل كنثله احساس بهزيستى ذهنى در رابطه بين هدفكرايى عملكردكريز و خودكارآمدى تحصيلى

\begin{tabular}{|c|c|c|c|c|c|}
\hline $\mathbf{P}$ & $\mathbf{t}$ & $\beta$ & SE & B & مثغيرهاى ييشبين \\
\hline$\% \cdots 1$ & g/TAF & $\cdot / \mu$ &.$/ M T r$ & 1/4es & هدف كرايى عملكرديريز \\
\hline 1.48 & $-r / r+9$ & -.1 .19 &.$/ 1 n$ &.$- / T M$ & هدف كرايى عملكرديريز \\
\hline.$\ldots 1$ & $r / \cdot \mid V$ & $\cdot / A \mid \Delta$ &.$/ N A$ & $r / r \cdot q$ & بهزيستى ذهنى \\
\hline.$\ldots 1$ & $-1 \% / 9 \cdot V$ &.$- / 98$ &.$/ M T$ & $-r / g 9 Q$ & هذف هرايى عملكردكريز \\
\hline$. \%+1$ & p/pir &.$/ M V$ &.$/ r q$. & V/1eq & بهزيستى ذهنى \\
\hline.$/ \ldots 1$ & IF/NE. & $\mathrm{V} / \mathrm{Tr}$ &.$/ .14$ & $\cdot / I V^{e}$ & هدف ترايى عملكردكريز × بهزيستى ذهنى \\
\hline
\end{tabular}

دوفصلنامه واوانشناسى معاصر

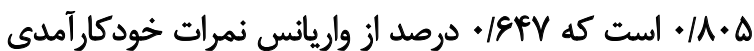

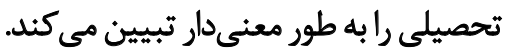

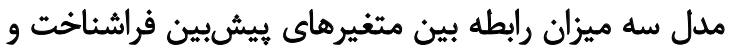

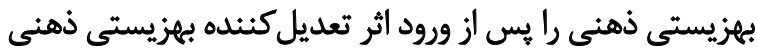

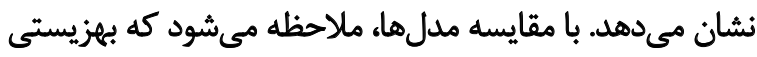

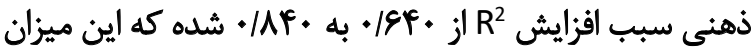

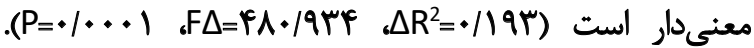

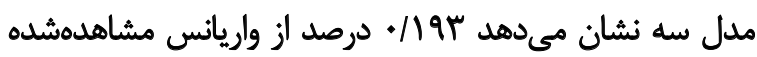

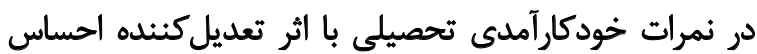

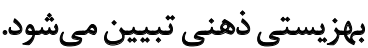

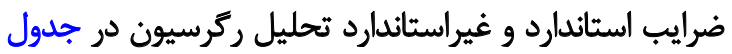

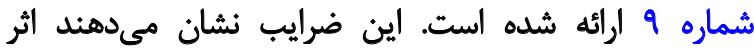

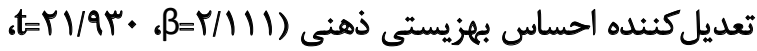
تحميا تحصيلى راتبيين كند.

$\stackrel{\leftrightarrow}{*}$

هدف اين ثيروهش بررسى نقش تعديل كنثنده احساس

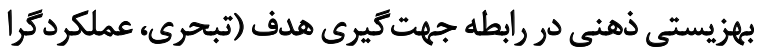

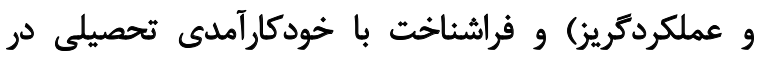

بهزيستى ذهنى نشان مىدهد. با مقايسه مدلها، ملاحظه

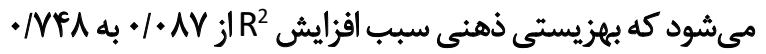

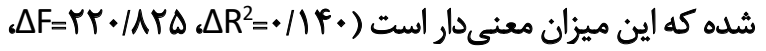

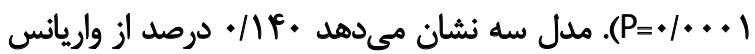

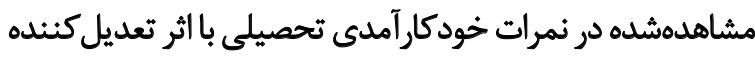
احساس بهزيستى ذهنى تبيين مى شيود.

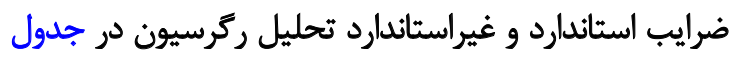

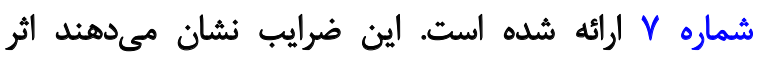

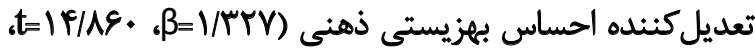

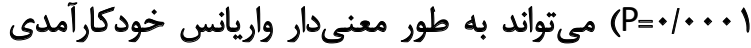
تحصيلى راتبيين كند. فرضيه هفتم: احساس بهزيستى ذهنى رابطه بين فراشناخت و خودكارآمدى تحصيلى رادر دانشجويان تعديل مى كند.

نتايج تحليل ركرسيون تعديلى به منظور بررسى نقش فرئس

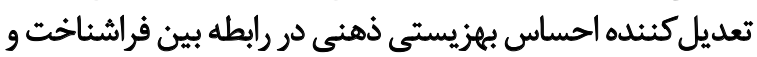

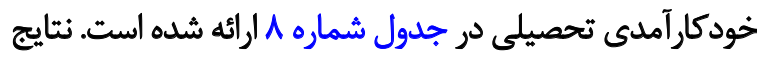

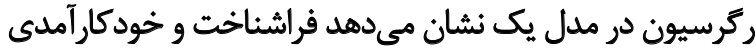

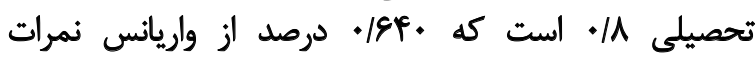

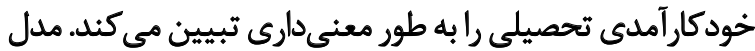

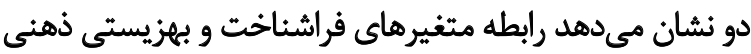

جدول A. نتايج تحليل ركرسيون تعديلى به منظور بررسى نقش تعديل كننده احساس بهزيستى ذهنى در رابطه بين فراشناخت و خودكارآمدى تحصيلى

\begin{tabular}{|c|c|c|c|c|c|c|}
\hline $\mathbf{P}$ & $\Delta \mathbf{F}$ & $\Delta \mathbf{R}^{r}$ & تعديلشده Rr & $\mathbf{R}^{r}$ & $\mathbf{R}$ & مدل \\
\hline$\cdot 1 \cdot \cdots 1$ & $V \cdot 9 / 9 r q$ & $\cdot|g|$ & . $\mid q 4$. & $\cdot|q 4|$ & $\cdot \mid \Lambda \cdot$ & 1 \\
\hline$\cdot / \cdot r$ & $N / \Delta q F$ & $\cdot / \cdot \wedge$ & . IGFV & $.194 \lambda$ & $\cdot \mid \Lambda \cdot \Delta$ & r \\
\hline$\cdot|\cdots|$ & $p \wedge \cdot / q m p$ & r & - /AF. & $\cdot|\lambda F|$ & $.191 \mathrm{~V}$ & r \\
\hline
\end{tabular}

دوفصلنامه لوانشناسى معاصر

مدل ا. متغير ييشبين: فراشناخت؛ مدل rا. متغيرهاي بيشبين: فراشناخت و بهزيستى ذهنى؛ مدل س. متغيرهاي بيشبين: فراشناخت و بهزيستى ذهنى و اثر

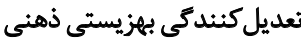


جدول 9. ضرايب استاندارد و غيراستاندارد تحليل ركرسيون نقش تعديل كننده احساس بهزيستى ذهنى در رابطه بين فراشناخت و خودكارآمدى تحصيلى

\begin{tabular}{|c|c|c|c|c|c|}
\hline $\mathbf{P}$ & $\mathbf{t}$ & $\boldsymbol{\beta}$ & SE & B & مثغيرهاى ييش بين \\
\hline$+1+.+1$ & releto & $\cdot / \Lambda+$. & $+1+v e$ & $r / \cdot 11$ & فراشناخت \\
\hline $.1 . . .1$ & s/us & . / QVVA & $\cdot / r \cdot 1$ & $1 / 20$ & فراشناخت \\
\hline $.1 .+e^{e}$ & T/QTI & $\cdot(M)^{\prime}$ & 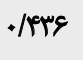 & $1 / T W$ & بهزيستى ذهنى \\
\hline $.1 . . .1$ & -NPF. & -.189 & $. / r .$. & $-1 / 8 M$ & فراشناخت \\
\hline $.1 . . .1$ & $-9 / \cdot 01$ & -.1811 & . & $-r / M P r$ & بهزيستى ذهنى \\
\hline$+1+\infty+1$ & rI/ar. & $r / M$ & $+1+\infty$ &.$/ M$ & فراشناخت : بهزيستى ذهنى \\
\hline
\end{tabular}

دوفصلنامه ووانشناسى معاصر

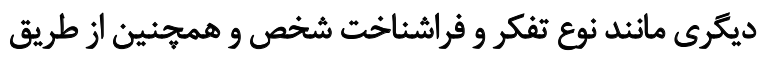

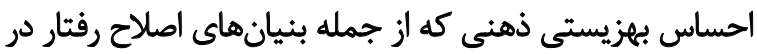

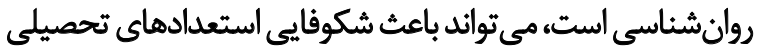

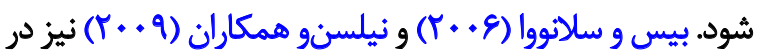

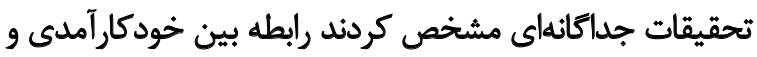

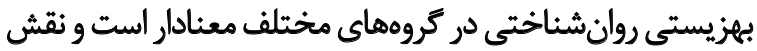

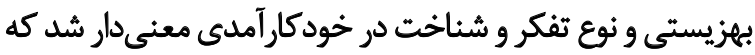
اين خود تأييدى بر يافته حاضر است.

از سوى ديكر در اين تحقيق نتايج ركرسيون تعديلى نشان داد

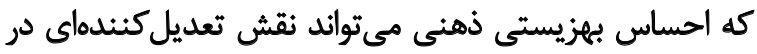

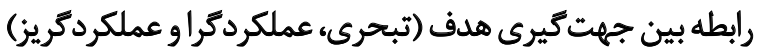

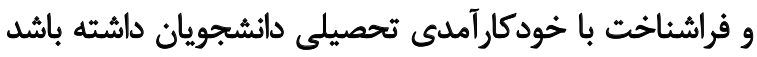

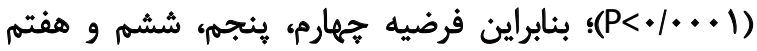

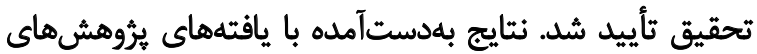

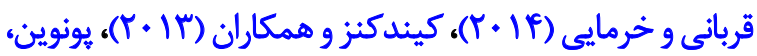

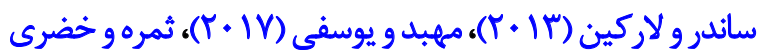

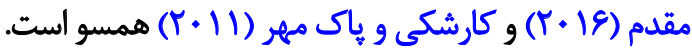

در تبيين اين فرضيه جنين مي إتوان استنباط كرد كه سلامت

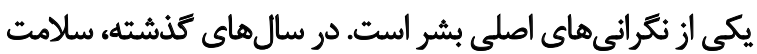

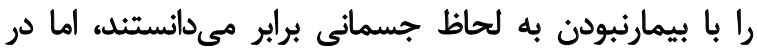

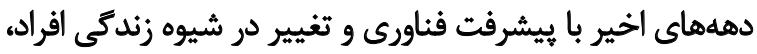

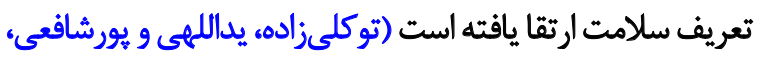

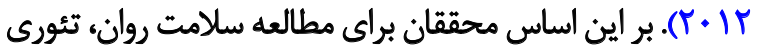

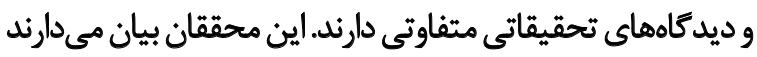

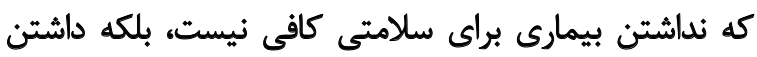

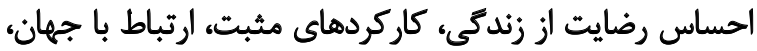

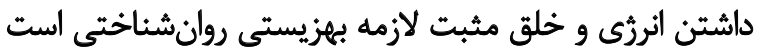

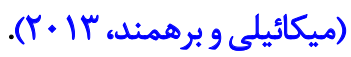

يكى از دورههاى زندكى كه مطالعه آن از نظر آنس احساس

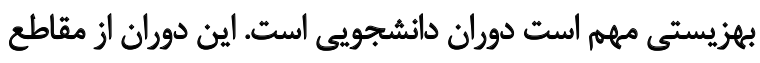

دانشجويان است. نتايج اين يُورهش نشان داد بين جهت

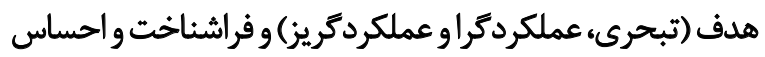

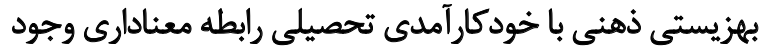

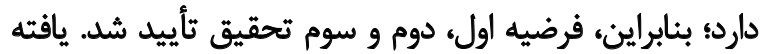

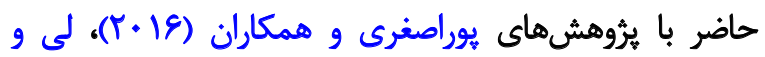

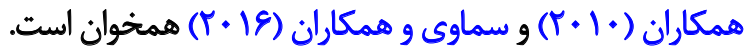

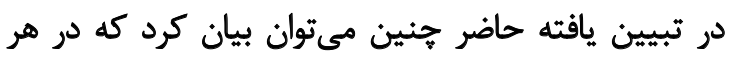

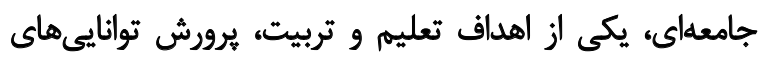

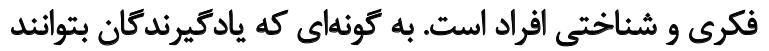

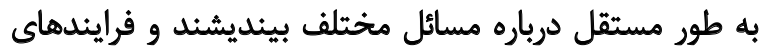

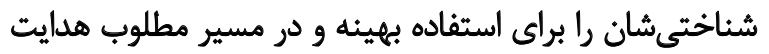

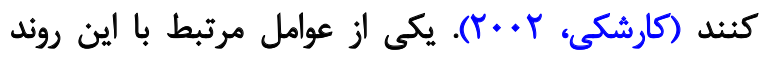

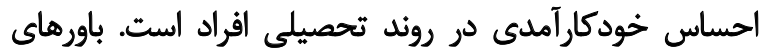

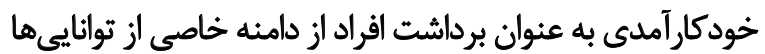

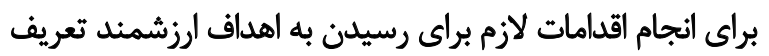

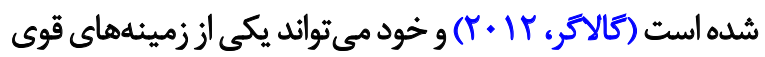
براي ايجاد موفقيتهاى تحصيلى شود.

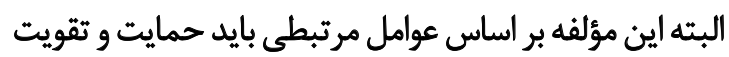

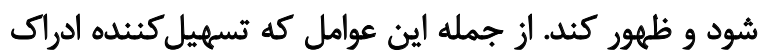

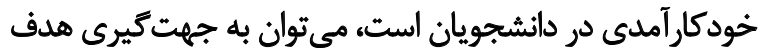

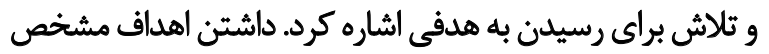

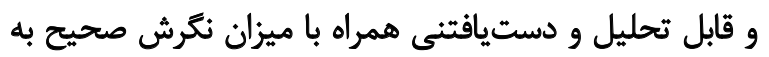

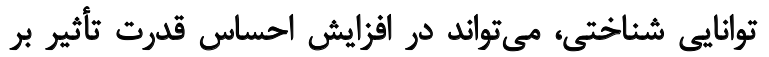

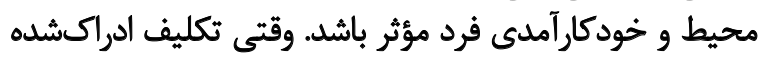

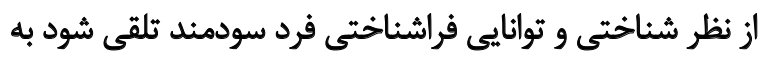

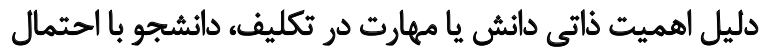

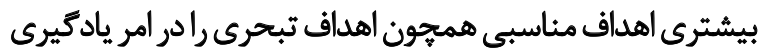
انتخاب مى كند (كرين، ميلر، كراوسون، داك و اكى، + +. ب). در اين صورت احساس خودكارآمدى تحصيلى احتمالاً در صورتى كه با تكيه بر هدفتزينى تبحرى همراه باشد با باعوامل احتل 
شناخت درباره شناخت يا دانش درباره دانستن معرفي مي كنده،

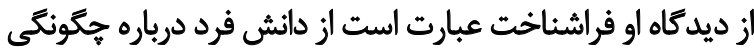

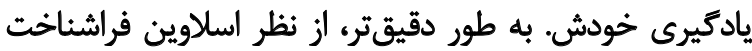

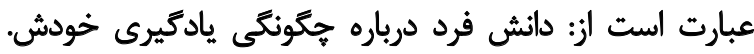

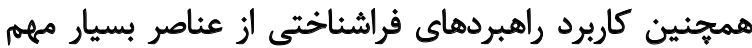

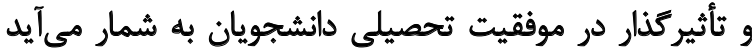

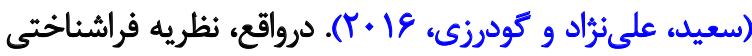

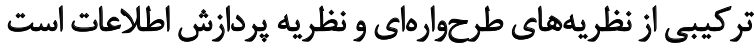

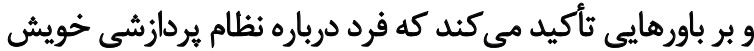

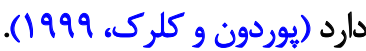

طبـق اين نظريه بسيارى از رفتارهاى مقابلهاى، ماهيت

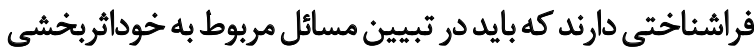

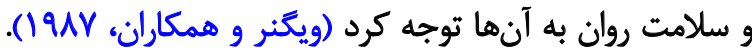

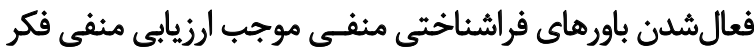

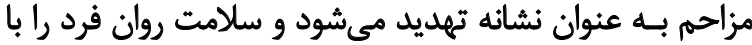

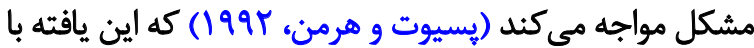
اين برؤوهش همسو است.

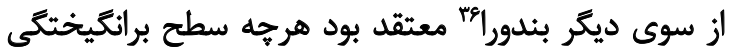

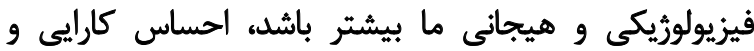

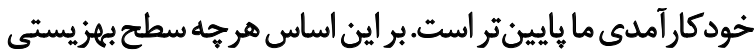

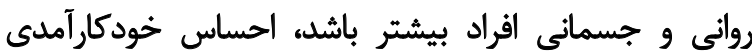

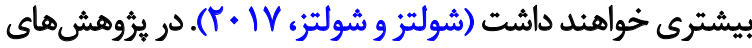
اخير به منظور كسترش ديد

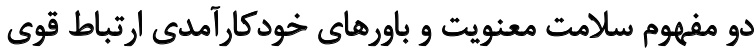

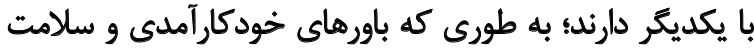

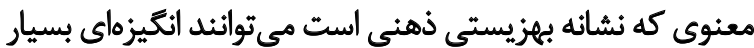

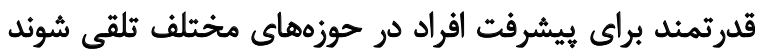

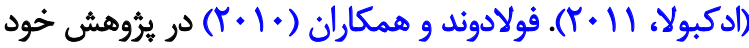

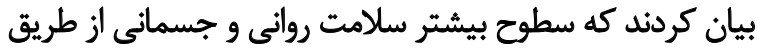

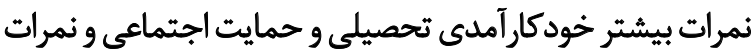

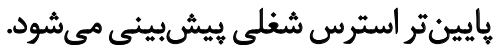

تحقيقات يرتو و بشارت (عالى يوربير كانى، صداقت و سحاقى،

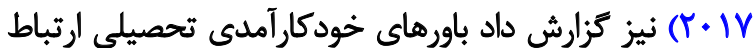

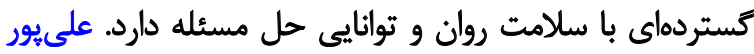

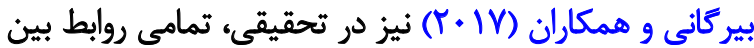

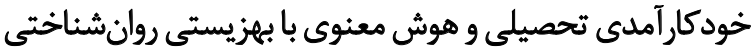

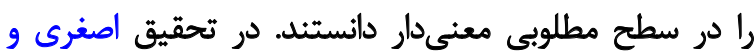

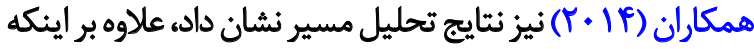

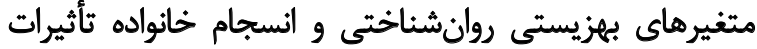

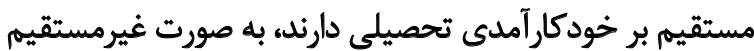

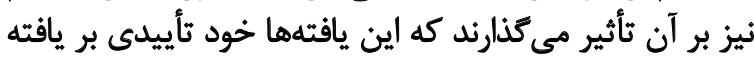

مهيج و يرجالش براى دانشجويان است. همه داتشجويان به دليل

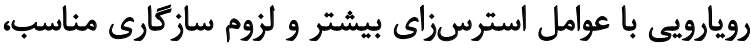

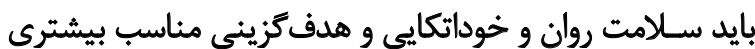

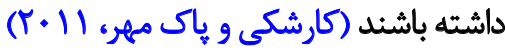

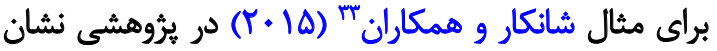

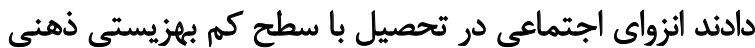

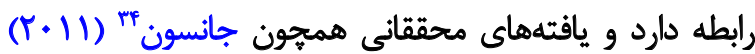

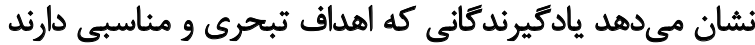

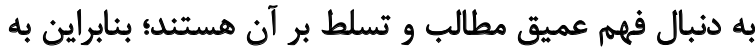

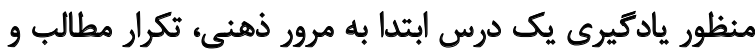

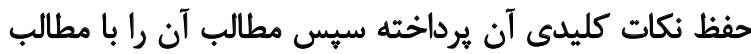

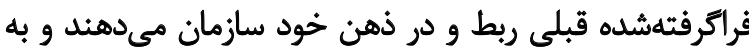

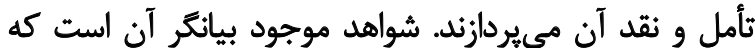

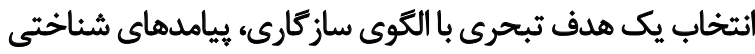

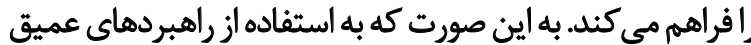
شناختى در يادكيرى منجر مى شود.

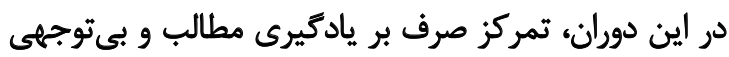

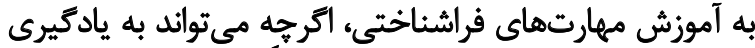

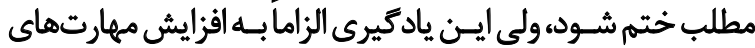

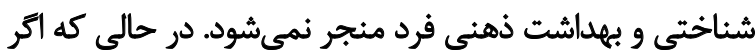

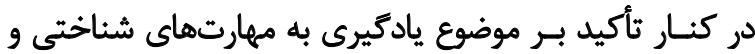

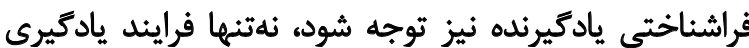

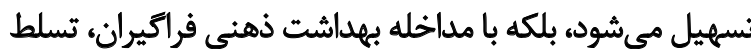

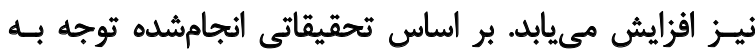

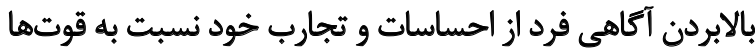

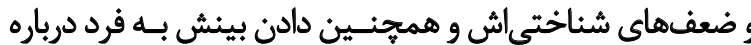

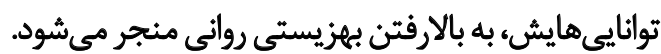
همجنين خودبازبينى كه شامل آموزش راهكارهايى مانند

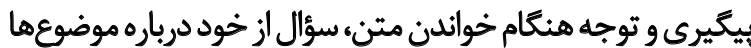

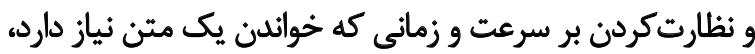

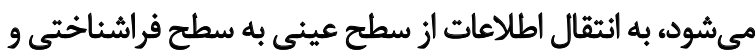

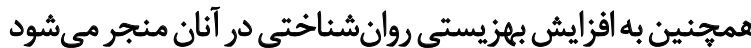

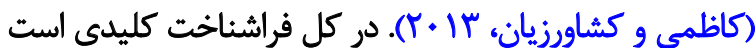

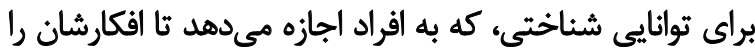

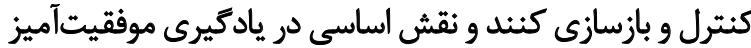

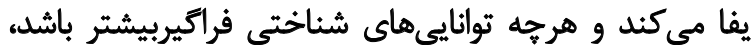
فرايند يادكيرى موفقيتآميز خواهد بود (عطار خامنه و سيف، فئن

. $(1$.

به عبارتى ديكر اسلاوينهّ (سيف، (1) فراشناخت را

33. Shankar, Rafnsson \& Steptoe

34. Janassen

35. Slavin 
حاضر است.

در بايان بايد بيان كرد اين تحقيق نيز با محدوديت هايى

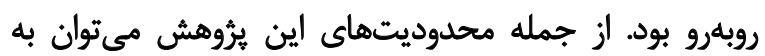

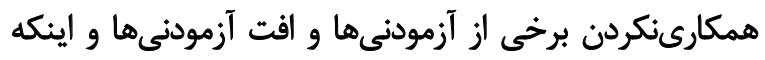

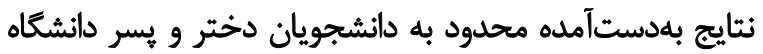

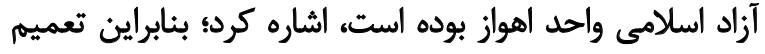
نتايج به كروههاي ديكر امكان يذير نيست. بر اين اساس بيشنهاد ميشود تا تحقيق در مناطق ديكر نيز

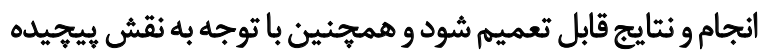

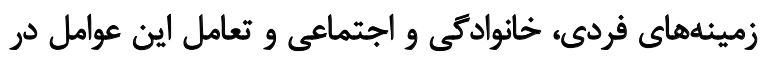

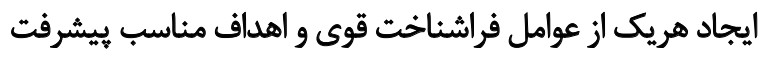

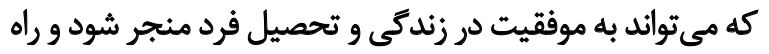

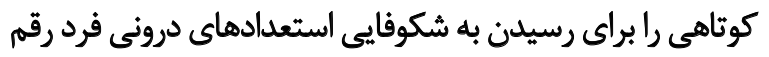

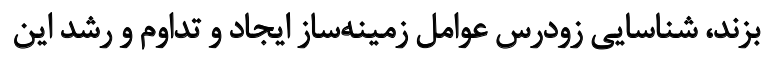

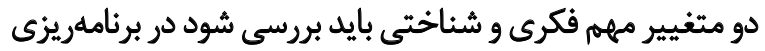

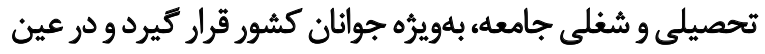

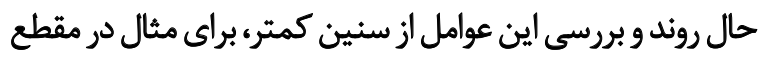
متوسطه و دبستان انجام كيرد.

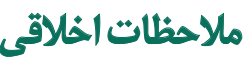

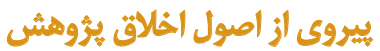

به منظور رعايت اصول اخلاقي، ييش از اجراى يرؤوهش تمامي

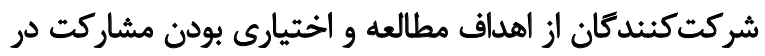

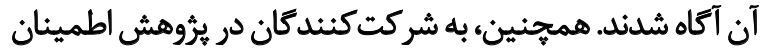

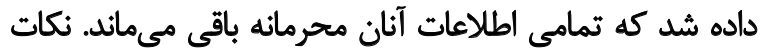

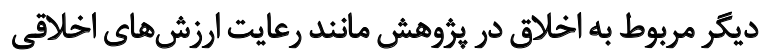
در جمعآورى دادهاو وعدم سوكيرى در تحليل دادهها نيز رعايت

$$
\text { مامي مالى }
$$

مقاله حاضر بركرفته از طرح برؤوهشى با حمايت مالى دانشكاه آزاد اسلامى واحد اهواز مىباشد.

$$
\text { تعارض مثأف }
$$

بنا به اظهار نويسنده اين مقاله تعارض منافع نداشته است.

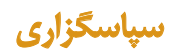

از تمام مسئولان، استادان و دانشجويان دانشعاه آزاد اسلامى

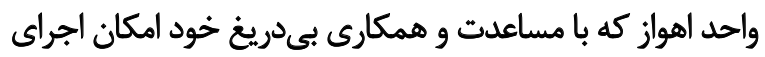
اين يُروهش را فراهم كردند، تشكر و قدردانى مى هـودئ. 


\section{References}

Abdellah, R. (2015). Metacognitive awareness and its relation to academic achievement and teaching performance of pre-service female teachers in Ajman University in UAE. Procedia-Social and Behavioral Sciences, 174(52), 560-7. [DOI:10.1016/j.sbspro.2015.01.707]

Adeqbola, M. (2011). Spirituality, self-efficacy, and quality of life among adults with sickle cell disease. Southern Online Journal of Nursing Research, 11(1), 5-9.

Alipour Birgani, S., Sedaghat, F., \& Saghaghi, H. (2017). [Investigating the relationship between academic self-efficacy and spiritual intelligence with psychological well-being of Jundishapur students in Ahvaz (Persian)]. Journal of New Advances in Behavioral Sciences, 1(1), 14-21.

Arrington-Sanders, R., Tsevat, J., Wilmott, R. W., Mrus, J. M., \& Britto, M T. (2006). Gender differences in health-related quality of life of adolescents with cystic fibrosis. Health Quality Life Outcomes, 4(1), 5-11. [DOI:10.1186/1477-7525-4-5] [PMID] [PMCID]

Asghari, F., Saadat, S., Atefi Karajvandani, S., Janalizadeh Kokaneh, S. (2014). [The relationship between academic self-efficacy and psychological well-being, family cohesion, and spiritual health among students of Kharazmi University (Persian)]. Iranian Journal of Medical Education, 14 (7), 581-93.

Atar Khamenah, F., Sef, A. A. (2010). [The effect of teaching metacognitive learning strategies on students' motivation and academic achievement (Persian)]. Journal of Educational Psychology Studies, 6(9), 57-74.

Beas, M. I. \& Salanova, M. (2006). Self-efficacy beliefs, computer training and psychological well-being among information and communication technology workers. Computers in Human Behavior, 22(6), 1043-58. [DOI:10.1016/j.chb.2004.03.027]

Benight, C., \& Bandura, A. (2004). Social cognitive theory of posttraumatic recovery: The role of perceived self-efficacy. Behaviour Research and Therapy, 42(10), 1129-48. [DOI:10.1016/j.brat.2003.08.008] [PMID]

Bernerth, J. B., \& Hirschfeld, R. R. (2016). The subjective well-being of group leaders as explained by the quality of leader-member exchange. Leadership Quarterly, 27(4), 697-710. [DOI:10.1016/j.leaqua.2016.04.003]

Besharat, M. A., Abbas Pourdopalani, T. (2010). [The relationship between metacognitive strategies and creativity with resiliency in students (Persian)]. Journal of Social Psychology, 5(14), 111-24.

Besharat, M. A., Etemadi Nia, M., Farahani, H. (2013). Anger and major depressive disorder: The mediating role of emotion regulation and anger rumination. Asian Journal of Psychiatry, 6(1), 35-41. [DOI:10.1016/j. ajp.2012.07.013] [PMID]

Blais, M.R., Valerand, R. J., Pelletier, I. G., \& Briere, N. M. (1989). French satisfaction with life scale. Canadian Journal of Behavioral science, satisfaction with life among Czech university students. Studia Psychological, 41, 239-44.

Carroll, A., Houghton, S., Wood, R., Unsworth, K., Hattie, J., Gordon, I., et al. (2009). Self-efficacy and acade achievement in Australian high school students: The mediating effects of academic aspirations and delinquency. Journal of Adolescence, 32(4), 797-817. [DOI:10.1016/j.adolescence.2008.10.009] [PMID]

Choi, N. (2005). Self-efficacy and self-concept as predictors of college student's academic performance. Journal of Psychology in Schools Banner, 42(2), 197-205. [DOI:10.1002/pits.20048]

Diener, E., Emmons, R. A., Larsen, R. J., \& Griffin, S. (1985). The satisfaction with life scale. Journal of Personality Assessment, 49(1), 71-5. [DOI:10.1207/s15327752jpa4901_13]
Dweck, C. S. (2000). Self-theories: Their role in motivation, personality and development. London: Psychology Press.

Efklides, A. (2006). Metacognition and affect: What can metacognitive experiences tell us about the learning process? Educational Research Review, 1(1), 3-14. [DOI:10.1016/j.edurev.2005.11.001]

Eleonora, P. L. (2003). The concept and instruction of metacognition. Teacher Development, 7(1), 44-61.

Farahani, M. T. (2009). [Individual differences in academic stress and subjective well-being: The role of stress coping styles (Persian)]. Journal of Research in Behavioural Sciences, 4(2), 81-93.

Fooladvand, Kh., Farzad, V., Shahraray, M., \& Sangari, A. A. (2010). [Role of social support, academic stress and academic self-efficacy on mental and physical health (Persian)]. Contemporary Psychology, 4(2), 81-93.

Gallagher, M. W. (2012). Self-efficacy. In V. N., Ramachandran (Eds.), Encyclopedia of Human Behavior (pp. 314-20). Cambridge: Academic Press.

Ghadampour, E. A., Mansouri, L., khaliligeshnigani, Z., \& Amraei, F. (2018) The effect of shoenaker's self encouragement training on loneliness felling and psychological well being. Quarterly Counseling Culture and Psychotherapy, 9(35), 147-70.

Gholami, F. (2010). [The relationship between social support and loneliness with life satisfaction in elderly men and women living in nursing homes in Ahvaz (Persian)] [MSc. Thesis]. Ahvaz: Islamic Azad University.

Ghorbani, R., \& Khormaie, F. (2014). [The effectiveness of self-regulation learning strategies training on the well-being psychology in female student (Persian)]. Paper presented at The $3^{\text {rd }}$ International Iranian Conference on Women's Health, Shiraz, Iran, 22 May 2014.

Greene, B. A., Miller, R. B., Crowson, H. M., Duke, B. L., \& Akey, K. L. (2004) Predicting high school students' cognitive engagement and achievement: Contributions of classroom perceptions and motivation. Con temporary Educational Psychology, 29(4), 462-82. [DOI:10.1016/j. cedpsych.2004.01.006]

Jaaskela, P., Poikkeus, A. M., Vasalampi, K., Valleala, U. M., \& Rasku-Puttonen, $H$. (2017). Assessing agency of university students: Validation of the AUS scale. Studies in Higher Education, 42(11), 2061-79. [DOI:10.10 80/03075079.2015.1130693]

Janassen, D. H. (2011). Learning to solve problems: A handbook for designing problem-solving learning environments. Abingdon: Routledge.

Kaplan, A., \& Murray, F. (2007). Technology, organizations and institution in the construction of economic value: The case of biotechnology. $\mathrm{Pa}$ per presentation at the Society for the Social Studies of Science Annual Meeting, Montreal, Canada, 11-13 October 2007.

Kareshki, H, Pakmehr, H. (2011). [The relationship between self-efficacy beliefs, meta-cognitive and critical thinking with mental health in medical sciences students (Persian)]. Hakim Research Journal, 14(3), 180-7.

Kareshki, H., Mirdoraghi, F., Hamzehlo, M. (2012). [The role of students\' achievement goals in their mental health (Persian)]. Quarterly Journal of Psychological Studies, 8(3), 159-78.

Karshki, H. (2002). [Application of metacognition in theoretical courses and patterns. engineering education reform (Persian)]. Paper presented at The Education Reform Conference, 21 June 2002.

Kazemi, H., Keshavarzian, F. (2013). [An assessment of the relationship between metacognitive states, problem solving and psychological wellbeing (Persian)]. New Educational Approaches, 7(1), 91-106 
Kevin, C., \& Gary, B. (2012). Student self-identity as a critical thinking, to type A behavior pattern. Journal of Research in Personality, 18(6), 212-23.

Kharshki, H., Kharazi, S. A. N., \& Ghazi Tabatabai, S. M. (2009). [Study of the relationship between perceptions of classroom environmental and development objectives; May type of school, field of study and location makes a difference? (Persian)]. Studies in Education and Psychology, 9(2), 79-84.

Kim, D., \& Lee, D. (2018). Impacts of metacognition on innovative behaviors: Focus on the mediating effects of entrepreneurship. Journal of Open Innovation: Technology, Market, and Complexity, 4(18), 1-9. [DOI:10.3390/joitmc4020018]

Kindekens, A. T., Reina, V. R., De Backer, F., Peeters, J., Buffel, T., \& Lombaerts, K. (2013). Enhancing student wellbeing in secondary education by combining self regulated learning and arts education. Social and Behavioral Sciences, 116(2014), 1982-7.

Komarraju, M., \& Nadler, D. (2013). Self-efficacy and academic achievement: Why do implicit beliefs, goals, and effort regulation matter? Learning and Individual Differences, 25, 67-72. [DOI:10.1016/j.lindif.2013.01.005]

Krejcie, R. V., \& Morgan, D. W. (1970). Determining sample size for research activities. Educational and Psychological Measurement, 30(3), 607-10. [DOI:10.1177/001316447003000308]

Lee, J. Q., McInerney, D. M., Liem, G. A. D., \& Ortiga, Y. P. (2010). The relationship between future goals and achievement goal orientations: An intrinsic-extrinsic motivation perspective. Contemporary Educational Psychology, 35(4), 264-79. [DOI:10.1016/j.cedpsych.2010.04.004]

Loughlin, J. E., \& Huebner, E. S. (2001). Life exprrience locus control and school satisfaction in adolescence. Social Indicators Research, 55, 156-83.

Mahbod, M., Yusefi, F. (2017). [Investigation of relationship between metacognition and self-handicapping with mediation of general self-efficacy (Persian)]. Biquarterly Journal of Cognitive Strategies in Learning, 5(8), 39-59.

Marino, P., Sirey, J. A., Raue, P., \& Alexopoulos, G. (2008). Impact of social support and self-efficacy on functioning in depressed older adults with chronic obstructive pulmonary disease. International Journal of Chronic Obstructive Pulmonary Disease, 3(4), 713-8. [DOI:10.2147/COPD.S2840]

Marofi, Y., Kord Koghabi, R., \& Saed Mocheshi, L. (2014). [The effectiveness of instructing cognitive and Meta cognitive strategies on academic achievement in experimental science lesson (Persian)]. Journal of Cognitive Strategies in Learning, 1(2), 83-96.

Midgley, C., Kaplan, A., Middleton, M., Maehr, M. L., Urdan, T., Anderman, L. H., et al. (1998). The development and validation of scales assessing students achievement goal orientations. Contemporary Educational Psychology, 23(2), 113-31. [DOI:10.1006/ceps.1998.0965] [PMID]

Mikaeili, N., \& Barahmand, U. (2013). Training in self-regulation enhances psychological well-being of distressed couples. Procedia-Social and Behavioral Sciences, 84, 66-9. [DOI:10.1016/j.sbspro.2013.06.511]

Mommersteeg, P. M., Herr, R., Bosch, J., Fischer, J. E., \& Loerbroks, A. (2011). Type D personality and metabolic syndrome in a 7-year prospective occupational cohort. Journal of Psychosomatic Research, 71(5), 357-63. [DOI:10.1016/j.jpsychores.2011.05.004] [PMID]

Navarro, D., Montserrat, C., Malo, S., González, M., Casas, F., \& Crous, G. (2017). Subjective well-being: what do adolescents say? Child \& Family Social Work, 22(1), 175-84. [DOI:10.1111/cfs.12215]
Nielsen, K., Yarker, J., Randall, R., \& Munir, F. (2009). The mediating effects of team and self-efficacy on the relationship between transformational leadership, and job satisfaction and psychological well-being in healthcare professionals: A cross-sectional questionnaire survey. International Journal of Nursing Studies, 46(9), 1236-44. [DOI:10.1016/j. ijnurstu.2009.03.001] [PMID]

O,Neil, H. F., \& Abedi, J. (1996). Reliability and validity of state metacognition inventory: Potential for alternative assessments. Journal of Educational Research, 189(4), 234-45.

O'Brien, M. E. (2014). A middle-range theory of spiritual well-being in illness. In M. E. O'Brien (Ed.). Spirituality in nursing: Standing on holly ground (pp. 63-71). Burlington: Jones \& Bartlett Learning.

Owen, S., \& Froman, R. D. (1988). Development of a college academic selfefficacy scale. Paper presented at The annual meeting of the Natioanl Council on Measurement in Education, New Orleans, United State, 5 August 1988.

Pesut, D. J., \& Herman, J. (1992). Metacognitive skills in diagnostic reasoning: Making the implicit explicit. The American Journal of Nursing, 3(4), 148-54. [DOI:10.1111/j.1744-618X.1992.tb00530.x] [PMID]

Philip, C. A., Bernard, M. R., \& Riddell, T. (2008). Instructional interventions affecting critical thinking skills and dispositions. Review of Educational Research, 78(4), 1102-34. [DOI:10.3102/0034654308326084]

Pintrich, P. R., \& Schunk, D. H. (2002). Motivation in education, theory, research, and application. Indianapolis: Merrill.

Pourasghar, N., Rezakiamanesh, A., Sarmadi, M., \& Zare, H. (2016). The predictive model of academic performance of students of distance education based on individual variables self-regulation strategies and motivational beliefs. International Journal of Humanities and Culture Studies, 2568-82.

Pulkka, A. T., \& Niemivirta, M. (2015). The relationships between adult students' achievement goal orientations, self-defined course goals, course evaluations, and performance. Journal for Educational Research Online, $7(3), 28-53$.

Purdon, C., \& Clark, D. A. (1999). Metacognition and obsessions. Clinical Psychology and Psychotherapy, 6(2), 102-10. [DOI:10.1002/(SICI)10990879(199905)6:23.0.CO;2-5]

Putwain, D., Sander, P., \& Larkin, D. (2013). Academic self-efficacy in studyrelated skills and behaviours: Relations with learning-related emotions and academic success. British Journal of Educational Psychology, 83(4), 633-50. [DOI:10.1111/j.2044-8279.2012.02084.x] [PMID]

Raggi, A., Leonardi, M., Mantegazza, R., Casale, S., \& Fioravanti, G. (2010) Social support and self-efficacy in patients with Myasthenia $G$ ravis: A common pathway towards positive health outcomes. Neurological Sciences, 31(2), 231-5. [DOI:10.1007/s10072-009-0194-8] [PMID]

Ramezani khamsi, Z., khademi Ashkezari, M., \& Naghsh, Z. (2017). [The relationship between emotional intelligence and academic achievement The mediating role of procrastination, self-regulation, self- efficacy (Persian)]. New Thoughts on Education Faculty of Education and Psychology, 13(3), 163-89.

Roberts, F. W. (2011). Effects of metacognition instruction on postsecondary student self-efficacy [MA. Thesis]. Austin, Texas: University of Texas at Austin.

Rode, J. C. (2005). Life satisfaction and student performance, Academy of management learning and education. Journal of Social Behavior and Personality, 4(3), 421-33. 
Saeed, N., Alinejad M., Godarzi, M. (2016). [The effectiveness of teaching cognitive strategies, metacognition on students self-directed learning readiness (Persian)]. Interdisciplinary Journal of Virtual Learning in Medical Sciences, 6(1), 39-47.

Saeedzadeh, M., Raeisoon, M. R., \& Mohammadi, Y. (2018). The relationship between cognitive and metacognitive strategies and academic achievement of students of Birjand University of Medical Sciences. Future of Medical Education Journal, 8(1), 27-30.

Saif, A. A. (2011). [Modern educational psychology (Persian)]. Tehran: Doran.

Salari, M. H., Pakdaman, Sh. (2010). [The role of meta-cognitive components in academic performance (Persian)]. Journal of Applied Psychology, 3(4), 102-12.

Samareh, S., Kezri Moghadam, N. (2016). [Relationship between achievement goals and academic self-efficacy; Mediation role of academic engagement (Persian)]. Education Strategies in Medical Sciences, 8(6), $13-20$

Samavi, S. A., Ebrahimi, K., Javdan, M. (2016). [Relationship between academic engagements, self-efficacy and academic motivation with academic achievement among high school students in Bandar Abbas (Persian)]. Biguartely Journal of Cognitive Strategies in Learning, 4(7), 71-92.

Sawhney, N., \& Bansal, S. (2015). Metacognitive awareness of undergraduate students in relation to their academic achievement. The International Journal of Indian Psychology, 3(8), 107-14.
Schultz, D. P., \& Schultz, S. E. (2017). Theories of personality [Y. Seid Mohammadi, Persian trans.]. Tehran: Virayesh.

Shankar, A., Rafnsson, S. B., \& Steptoe, A. (2015). Longitudinal associations between social connections and subjective wellbeing in the English Longitudinal Study of Ageing. Psychology \& Health, 30(6), 626-92. [DOI:10.1 080/08870446.2014.979823] [PMID]

Tavakolizadeh, J., Yadollahi, H., \& Poorshafeic, H. (2012). The role of Selfregulated learning strategies inpsychological wellbeing condition of students. Social and Behavioral Sciences, 69, 807-15.

Trevathan, V. (2002). [A profile of psychosocial, learning style, family, and academic selfefficacy characteristics of the transition program students at North Carolina State University [PhD. Dissertation]. Raleigh: North Carolina state university.

Was, C. A., \& Beziat, T. L. (2015). Exploring the Relationships between goal orientations, knowledge monitoring and academic achievement. Journal of Education and Human Development, 4(3), 67-77.

Wegner, D. M., Schneider, D. J., Carter, S. R., \& White, T. (1987). Paradoxical effects of thought suppression. Journal of Personality and Social Psychology, 53(1), 5-13. [DOI:10.1037/0022-3514.53.1.5]

Ziegler, M., Schmukle, S., Egloff, B., \& Bühner, M. (2010). Investigating measures of achievement motivation. Journal of Individual Differences, 31(1), 15-21. [DOI:10.1027/1614-0001/a000002] 
This Page Intentionally Left Blank 